\title{
The context of female dispersal in Kanyawara chimpanzees
}

\section{Citation}

Stumpf, Wrangham, Emery Thompson, and Muller. 2009. "The Context of Female Dispersal in

Kanyawara Chimpanzees." Behaviour 146 (4) (April 1): 629-656. doi:10.1163/156853909x413853.

\section{Published Version}

doi:10.1163/156853909x413853

\section{Permanent link}

http://nrs.harvard.edu/urn-3:HUL.InstRepos:26372958

\section{Terms of Use}

This article was downloaded from Harvard University's DASH repository, and is made available under the terms and conditions applicable to Open Access Policy Articles, as set forth at http:// nrs.harvard.edu/urn-3:HUL.InstRepos:dash.current.terms-of-use\#OAP

\section{Share Your Story}

The Harvard community has made this article openly available.

Please share how this access benefits you. Submit a story.

Accessibility 
4

5Manuscript for Behaviour:

6Special Issue on Primate Dispersal (Katherine Jack and Lynne Isbell, Eds.)

7

10Title: The Context of Female Dispersal in Kanyawara Chimpanzees

11

12

13Short Title: Female Dispersal in Chimpanzees

14

15

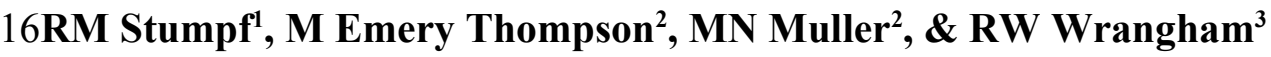

$17^{1}$ Department of Anthropology, University of Illinois, ${ }^{2}$ Department of Anthropology,

18University of New Mexico, ${ }^{3}$ Department of Anthropology, Harvard University

19

20

21

22

23

24Corresponding Author:

25

26Rebecca M Stumpf

27Department of Anthropology

28109 Davenport Hall

29607 South Mathews Avenue

30Urbana, IL 61801

31rstumpf@uiuc.edu 


\section{Summary}

34In most social mammals, members of either one sex or both leave their natal group at sexual 35maturity. In catarrhine primates, male emigration is the predominant pattern. Female philopatry 36 facilitates cooperation among kin, and female reproductive success is influenced by these 37relationships. Chimpanzees (Pan troglodytes) are unusual in that dispersal is almost exclusively 38by females. While plausible ultimate hypotheses can explain this dispersal pattern, the 39proximate causes of female dispersal are unknown and warrant examination due to variation in 40dispersal behavior and the associated high costs of immigration. In this study, we examine the 41 behavioral and hormonal context of female dispersal in chimpanzees of Kibale National Park, 42Uganda, in order to understand variation in dispersal patterns and gain insight into functional 43explanations. Using over 10 years of behavioral, endocrinological, and demographic records, we 44examined the significance of 5 potential predictors of the timing of dispersal: (1) maturational 45state; (2) association patterns; (3) mating patterns; (4) physiological stress; and (5) feeding 46ecology. Female dispersal was not strictly predicted by chronological or gynecological age, and 47dispersal did not correlate with shifts in glucocorticoid levels. We found no evidence that 48females avoided mating in their natal group, even with known relatives, suggesting that 49inbreeding avoidance is not a sufficient proximate explanation for dispersal in chimpanzees.

50Instead, variation in social development and the availability of energy for dispersal were 51 implicated and necessitate more intensive examination along with subtler variation in 52 maturational trajectories.

\section{3}

\section{Keywords: dispersal, adolescence, stress, inbreeding, energetics}




\section{INTRODUCTION}

59In most social mammals, members of one or both sexes leave their natal group at sexual maturity 60to avoid inbreeding (Pusey \& Packer, 1987). For catarrhine primates, female philopatry and male 61dispersal are the predominant pattern (Pusey \& Packer, 1987; Melnick \& Pearl, 1987; Wrangham 621987). Philopatric females enjoy a variety of benefits from long-term cooperation with kin, 63including enhanced access to resources and reduced infant mortality (Wrangham, 1980; Silk et 64al., 2003).

65

66Chimpanzees (Pan troglodytes) are unusual among Old World Primates in that dispersal is 67almost exclusively by females (Goodall, 1986). Ultimate factors affecting this unusual pattern of 68dispersal include the importance of male affiliation and cooperation for defense of the 69community feeding range, the size of which affects female reproductive rates (Williams et al., 702004). However, the proximate causes of female dispersal in chimpanzees are unclear, both 71 because the timing of dispersal varies, and because some females never leave their natal 72communities (e.g., Goodall, 1986; reviewed in Stumpf, 2007).

73

74While males in various species may benefit by seeking groups with improved mating 75opportunities (Jack \& Fedigan, 2004a,b; Fedigan \& Jack, 2004), females receive few obvious 76benefits and face high costs of dispersal. Access to high quality food resources is critical for 77female reproductive success (Bradbury \& Vehrencamp, 1977; Emlen \& Oring, 1977; Trivers, 781972; for chimpanzees: Emery Thompson et al., 2007a; Emery Thompson \& Wrangham, 2008). 79Food acquisition in chimpanzees is challenging because resources are patchily distributed in both 80time and space. Moreover, relative social status is a key predictor of resource access (Murray et 81al., 2006; Kahlenberg et al., 2008a). Consequently, a key cost of emigration is the loss of 
82affiliative natal relationships and knowledge of food resource locations (Smuts, 1993; Alberts \& 83Altmann, 1995a,b; Williams et al., 2002). In other primates, adolescents can be forcibly expelled 84from the natal group (e.g. Crockett \& Pope, 1993), increasing the relative cost of philopatry 85(Pusey \& Packer, 1987; Moore, 1984). However, this does not occur in chimpanzees. Instead, 86females leave without being coerced, enter a new group at the bottom of the social hierarchy, 87receive considerable aggression from resident females, and must fight to establish a residential 88core area: these are costly activities associated with elevations in stress hormone production 89(Townsend et al., 2007; Kahlenberg et al., 2008a,b; Pusey et al., 2008). One major benefit of 90dispersal is avoidance of the negative effects on reproductive fitness caused by breeding with 91close kin (Moore \& Ali, 1984). However, while inbreeding avoidance provides a plausible 92ultimate explanation for sex-biased dispersal in primates generally, and male cooperative 93territoriality presents a reasonable explanation for male philopatry in chimpanzees specifically, 94the proximate behavioral and biological mechanisms underlying female dispersal in chimpanzees 95are poorly understood.

96

97The purpose of this study was to document behavioral and physiological changes in adolescent 98female chimpanzees so as to test potential proximate mechanisms for the timing of their dispersal 99to a new community. We tested 5 non-mutually exclusive hypotheses:

100 (1) Dispersal is consistently related to sexual maturation, such that (a) female emigration 101 corresponds to the onset of sexual cycling, or (b) females who reach sexual maturity 102 earlier emigrate at an earlier age. Female emigration is frequently coincident with sexual 103 receptivity in chimpanzees (Nishida, 1979; Pusey, 1979, 1980; Boesch and Boesch104 Achermann, 2000) as in some other primates (Jolly et al., 1982; Moore, 1984), but it is 105 not known how the timing of female chimpanzee dispersal is related to the onset of 106 sexual maturity. 
107 (2) Dispersal is correlated with the risk of inbreeding, such that females avoid mating with

108 related males in their natal community. Females were reported to avoid mating with close

109 kin (Pusey, 1980; Wrangham, pers. comm.), but the proximate role of inbreeding

110 avoidance in influencing individual dispersal decisions is unknown.

111 (3) Dispersal is predicted by social relationships, such that (a) shifts in association patterns

112 precede emigration, and/or (b) association patterns differ between females who emigrate

113 early, late or not at all. In adolescent Gombe chimpanzees, female sexual maturation is

114 associated with a shift from exclusive association with the mother to association with

115 adolescent and adult males that precedes emigration (Pusey, 1990; Goodall, 1986). The

116 quality of female social relationships (e.g. aggression from adult females) might also

117 influence the relative costs and benefits of dispersal.

118 (4) Dispersal is correlated with stress, as measured by urinary cortisol levels, such that (a)

119 females emigrate when experiencing greater stress, and/or (b) adolescents with generally

120 higher stress levels emigrate earlier. Increased stress hormones could be associated with

121 any of the previously-described predictors and might mediate detachment from the natal

122 community, as in willow tits (Parus montanus: Silverin, 1997) or winged insects (e.g.

123 Cardiocondyla obscurior: Cremer \& Heinze, 2003).

124 (5) Dispersal corresponds with changes in resource availability in the natal habitat. There are

125 two opposing predictions. Females may emigrate only during periods of high fruit

126 consumption when they have sufficient energy reserves to face a period of resource

127 uncertainty (e.g., screech-owls (Otus kennicottii), Belthoff \& Dufty, 1998).

128 Alternatively, low dietary quality may lead young females to seek improved foraging

129 opportunities in other habitats (e.g. Lurz, et al., 1997; Nunes et al., 1999).

130. 


\section{METHODS}

\section{Study site}

134We studied wild chimpanzees (P.t. schweinfurthii) of the Kanyawara community in Kibale 135National Park, western Uganda $\left(0^{\circ} 34^{\prime} \mathrm{N}\right.$ and $\left.30^{\circ} 21^{\prime} \mathrm{E}\right)$. The Kanyawara chimpanzees range over 136approximately $32 \mathrm{~km}^{2}$ of medium altitude habitat, comprising areas of moist evergreen primary 137 forest, logged regenerating forest, grassland, swamp, and agriculture (Chapman \& Wrangham, 1381993). R. Wrangham established the Kibale Chimpanzee Project in 1987, following earlier work 139by Isabirye-Basuta (1988, 1989), and research has been continuous since then (Wrangham et al., 1401996). Individual chimpanzees are well habituated to human observers, and have never been 141 provisioned.

\section{2}

\section{Study subjects and age estimation}

144The Kanyawara chimpanzee community currently consists of 10 adult males, 16 adult females 145and 23 immature males and females. We extracted relevant data on reproductive parameters and 146dispersal events from long-term behavioral records collected over a fourteen year period between 1471994 and 2007. During this period, we studied 22 nulliparous females, including 8 immigrants 148aged at least 10 years and 14 natal Kanyawara females aged at least 5 years (Table I). Of the 149natal females studied, 10 had birthdates known to within one month. Four natal females born in 150the 1980s and 8 immigrant females have birthdate estimates based on observer estimations of 151their body size at first sighting relative to individuals of known age.

\section{2}

153Females who were last observed in healthy condition between the ages of about 9-15 are 154assumed in these data to have emigrated, or attempted emigration. However, we do not have 155records from neighboring chimpanzee communities to confirm dispersal, nor do we often recover 
156the remains of dead chimpanzees. We present these data with the caveat that some assumed 157emigrants may have died in the natal community. In one case (JK), dispersal was confirmed by 158her revisiting the Kanyawara community briefly, several years after her initial departure.

\section{Reproductive data}

161We used Kaplan-Meier survival analyses to calculate time interval data, such as the age of 162emigration or the interval between first maximal sexual swelling (defined as the first 163 unambiguous observation of tumescence of both vaginal and perianal tissue without occurrence 164of wrinkling (Dahl et al., 1991) and emigration. This method increases statistical power by 165including censored datapoints (e.g., females who had experienced a swelling but had not yet 166emigrated). We provide the mean and standard error from the Kaplan-Meier analysis, the 167number of uncensored $(\mathrm{Nu})$ and censored $(\mathrm{Nc})$ datapoints, and the range of uncensored events. 168For age of emigration, we performed each analysis for the set of females with known dates of 169birth (to within one month) and again with the larger sample that includes females with estimated 170birthdates.

172Two sources of bias might impact behavioral observations of new community members.

173Unhabituated individuals may be wary of human observers or of group members, and it may take 174time for the field staff to reliably identify individual immigrants. We do not believe these biases 175have affected our findings. First, observers note identifying characteristics of unidentified 176females and record their presence and all behaviors involving them as they would with a known 177individual. Once a female is established and named, which typically takes less than one month, 178we are able to update records of her presence from her initial sighting onwards. For example, 179when we note the interval between immigration and first copulation, we have verified this 180against copulation records of 'unidentified' females. Thus, we believe that our behavioral records 
181 for each immigrant female are complete from the time of her first being seen in Kanyawara 182parties. Second, observation rates of the immigrant females during their first six months in the 183community were higher than those of natal adolescents overall (mean \pm S.E.: natal: $345 \pm 165$ 184hrs/month, immigrants $447 \pm 114 \mathrm{hr} /$ month) and during estrus, specifically (natal: $125 \pm 67$ 185hrs/month, immigrants: $232 \pm 78 \mathrm{hrs} /$ month). In fact, our ability to observe immigrants is 186enhanced by their tendency to affiliate with large groups of males as a counterstrategy to the 187aggression they receive from resident females (Kahlenberg et al., 2008b).

\section{Association Patterns}

190Association data were recorded as a part of continuous data collection. KCP field staff conduct 191daily observations, following one chimpanzee party, when possible, from nest to nest, recording 192the identities of all individuals in the party every 15 minutes. We analyzed the association 193patterns of target females with a) juvenile males and females (5-8 years of age) excluding the 194target's dependent siblings, b) adolescent females (9-15 years of age), c) adolescent males (9-14 195years of age), d) adult females ( $>15$ years of age, excluding each target's mother), e) adult males 196( $\geq 15$ years $)$ and $f$ ) each target's mother.

\section{7}

198Association rates were determined by obtaining a simple ratio association index for each 199adolescent female with each individual in the community (Cairns \& Schwager, 1987; Ginsberg 200\& Young, 1992). The simple index is calculated for each dyad as $X /\left(X+Y_{\mathrm{AB}}+Y_{\mathrm{A}}+Y_{\mathrm{B}}\right)$, where $X$ is 201 the number of scans during which $\mathrm{A}$ and $\mathrm{B}$ were observed together, $Y_{\mathrm{AB}}$ is the number of scans

202during which A and B were both observed in separate groups, $Y_{\mathrm{A}}$ is the number of scans during 203which only A was observed, and $Y_{\mathrm{B}}$ is the number of scans during which only B was observed. 204This ratio was calculated for each year (age 9-15 or until emigration or parturition) of the target 205female. These ratios for each female were then averaged by age class (all juvenile males and 
206females, adolescent males and females, adult males and females and mothers) for each year and 207then a final association index for each age class was obtained for each female by averaging 208across all years she was aged 9-15 (or until emigration or parturition). Individuals (from any age 209class) present for fewer than 25 observations per year were excluded from analyses.

211We used the simple index (Cairns \& Schwager, 1987) because, relative to other association 212indices (e.g. half-weight or twice-weight indices (Cairns \& Schwager, 1987), the simple index is 213statistically unbiased (Ginsberg \& Young, 1992) and is more appropriate in situations where 214associations are determined by membership in the same group (Whitehead \& Dufault, 1999). 215 Nevertheless, we did compare the patterns in our results from the simple index to two other 216association indices, the half-weight index and another dyadic association index, calculated as the 217 number of scans an individual was present with the female of interest divided by the total 218number of scans the female was present. All three indices supported the same association 219patterns.

220

\section{Sexual behavior}

222The KCP field staff recorded all attempted and completed copulations during daily observations. $223 \mathrm{We}$ analyzed the copulation patterns of adolescent females with adult males ( $\geq 15$ years of age) 224as a rate per hour of observation while in maximal swelling. Rates were calculated for each four 225 month period beginning with the first observation of maximal sexual swelling in the community 226and ending with emigration, conception, or last available data (Dec. 2006); periods with fewer 227than 20 estrous observation hours were excluded. This left us with copulation data for 12 228females: 7 immigrants and 5 natal females. 
230Whenever possible, the initiator of the copulation was noted. The male was considered to have 231 initiated the copulation if he approached the female for intromission or performed a clear 232solicitation behavior (e.g., penis-flicking, branch-shaking) to the female. Female-initiation was $233 d e f i n e d$ by female approach without solicitation by the male, leading to copulation. In $65 \%$ of 234the adolescent female copulations there was one clear initiator, and 10 females had at least 10 235such copulations. For each of these females, we calculated the number of copulations she 236initiated as a proportion of all her copulations with a single clear initiator.

\section{7}

238Finally, we looked at mating partner diversity by calculating the percentage of potential adult 239male partners with which each female mated and the variance in copulation frequency across all 240males, each plotted against the total number of copulations observed for the female.

\section{Glucocorticoid data}

243Routine collection of chimpanzee urine was initiated at Kanyawara in November 1997, and has 244continued through the present day. Detailed information on collection and storage methods is 245presented by Muller \& Wrangham (2004a, b) and Emery Thompson (2005). Samples were ana246lyzed for cortisol using enzyme-immunoassay reagents provided by C.J. Munro at the University 247of California at Davis and protocols previously described for use with chimpanzees (Muller et 248al., 2007; Kahlenberg et al., 2008b). Interassay coefficients of variation for this assay were 11.5 249and 14.4\% $(\mathrm{N}=94)$ for high and low pools, respectively. Intra-assay coefficients of variation for 25012 replicates were 5.4 and $9.5 \%$ for high and low pools, respectively. To correct for variation in 251 urine concentration, cortisol values were indexed to creatinine, which was quantified colorimetri252cally. Samples with creatinine measurements below $0.05 \mathrm{mg} / \mathrm{ml}$ were excluded from all analyses. 
255Cortisol shows a distinct circadian pattern in chimpanzee urine, with levels peaking in the early 256morning, and subsequently declining throughout the day (Muller \& Lipson, 2003). To correct 257 for this, we first calculated a regression equation of hour of the day versus cortisol (in $\mathrm{ng} / \mathrm{mg}-\mathrm{Cr}$ ) 258 for each of 14 Kanyawara females from whom we have collected 50 or more samples $($ mean $=$ 25982 samples), then we averaged the slopes (-11.3 \pm 1.2 S.E.) and intercepts $(253.5 \pm 16.0)$. This 260 circadian pattern was consistent across age groups. Following previous analyses (Kahlenberg et 261al., 2008a), we calculated cortisol values as the time-adjusted residual of this average regression 262line. These values provide an intuitive gauge of relative cortisol elevation: the "expected" 263 cortisol residual of any female sample is zero (mean of 3064 female samples $=4.2$ ), with positive 264or negative values representing titers greater or less than expected. To place cortisol fluctuations 265 of adolescents in perspective with other females, we present plots with a y-axis that represents \pm 2661 standard deviation $(168, \mathrm{~N}=3064)$ of all Kanyawara female cortisol titers assayed to date. To 267 further correct for uneven sampling, we calculated a single daily average when multiple samples 268had been taken and then derived a monthly average for each individual for use in the final 269analyses.

270

$271 \mathrm{We}$ calculated age patterns of cortisol for natal females only, as our research group has 272previously documented significant elevations in the cortisol levels of new immigrants 273(Kahlenberg et al., 2008b). We analyzed samples from females beginning at the age of 5 and 274ending with death, dispersal, or conception. One female (JK) received a severe wire snare injury 275 at age 13 which was accompanied by elevated cortisol levels. For this female, we examined only 276samples collected prior to the injury. We calculated the female mean at each age (by year) and, 277 excluding age classes represented by a single subject, computed a linear regression to test for

278trends. We considered both chronological age (time since birth) and gynecological age (time 
279since first maximal sexual swelling). For emigrants, we conducted a similar analysis using 6 280 month intervals during the three years prior to emigration.

\section{1}

\section{Diet}

283We quantified changes in energy availability in Kanyawara by examining variation in the 284monthly consumption of fruit (see Emery Thompson \& Wrangham, 2008). During daily 285observations, feeding behavior of the chimpanzee party was recorded every 15 minutes. We 286calculated the percentage of observations in which chimpanzees ate fruit as a proportion of all 287observations in which chimpanzees fed. At Kanyawara, this measure of dietary quality is 288significantly correlated with fruit availability estimates obtained from phenological transects 289(Wrangham et al., 1991, 1996; Sherry, 2002) and with biomarkers of chimpanzee energetic 290condition (C-peptide of insulin, Emery Thompson et al., 2009).

291

\section{RESULTS}

293

\section{Timing of Dispersal}

295Females of known age who emigrated from Kanyawara did so at an average age of 12.6 years $296(\mathrm{SE}=1.0, \mathrm{Nu}=4, \mathrm{Nc}=5$, range: $10.4-15.1)$. Adding natal females of estimated age gives us a 297slightly higher figure of 12.9 years $(\mathrm{SE}=0.7, \mathrm{Nu}=8, \mathrm{Nc}=5$, range: $10.4-15.7)$. This is 298 consistent with the average age estimates of 13 years that we assigned to 8 new immigrants. The 299interval between sexual maturity, as defined by the first maximal swelling, and emigration was 300highly variable. Two of eight emigrating females were not observed with a maximal swelling 301 prior to their disappearance. The interval to emigration for the six females who experienced 302prior maximal swellings was an average of 15.5 months $(\mathrm{SE}=3.4$, range $=1.2-22.7)$. One natal 303 female remained in Kanyawara to breed. Because first swellings typically preceded emigration, 
$304 f$ females who matured at a later age also dispersed at a later age $\left(r_{s}=0.83, N=8, p=0.027\right)$.

305However, there was no significant relationship between a female's age at sexual maturity and her

306subsequent latency to dispersal $\left(\mathrm{r}_{\mathrm{s}}=0.26, \mathrm{~N}=8, \mathrm{p}=0.5\right)$. With one exception, immigrants were

307 sexually mature when first identified. The one exception was not observed with a swelling for

308approximately 1 year.

309

\section{Mating Behavior and Inbreeding Risk}

311Five of seven natal females copulated with an adult male during their first maximal swelling 312cycle. Natal females were first seen to copulate with adult males an average of 0.7 months after 313their first sexual swelling $(\mathrm{SE}=0.5, \mathrm{Nu}=7, \mathrm{Nc}=0$, range: $0-3.7)$, whereas immigrants first 314 copulated with an adult Kanyawara male an average of 2 months after their first swelling in the 315 community $(\mathrm{SE}=0.9, \mathrm{Nu}=7, \mathrm{Nc}=0$, range: $0-4.8)$. The only natal female to give birth (LR) 316did so 37.0 months after her first sexual swelling. Immigrants experienced an average delay of 31726.9 months before birth $(\mathrm{SE}=3.3, \mathrm{Nu}=5, \mathrm{Nc}=3$, range: $10.6-36.8$; n.b., gestation length in 318chimpanzees is approximately 230 days, Wallis 1997; Shimizu et al. 2003).

320There was a significant positive relationship between gynecological age (defined here as the time 321 since first observed maximal sexual swelling in the Kanyawara community), and copulation rate 322 with adult males $\left(\mathrm{R}^{2}=0.51, \mathrm{df}=7, \mathrm{p}=0.047\right.$, Figure 1$)$. There was no significant difference 323between natal females and immigrants in their rates of copulation, matched for gynecological age 324group (Wilcoxon matched-pairs test, $\mathrm{z}=-1.69, \mathrm{~N}_{1}=\mathrm{N}_{2}=7$ age groups, $\mathrm{p}=0.09$ ). One natal 325 female (LR) maintained consistently higher copulation rates than all other adolescent females. 326This individual was the sole natal female who did not emigrate from the community. Comparing 327 immigrant females with only the natal females who later emigrated, we did find a significant 328difference, with immigrant females copulating at moderately higher rates in each age group $(\mathrm{z}=$ 
329-2.032, $\mathrm{N}_{1}=\mathrm{N}_{2}=5, \mathrm{p}=0.042$ ). However, even these differences were small when considered 330against the high copulation rates generally achieved by chimpanzees (Watts, 2007; Wrangham, 3312002): during the first 2 years of sexual cycling in the community, immigrants had an average 332rate of 0.15 copulations/hour, while natal emigrants had copulation rates of 0.11 333 copulations/hour.

334

335 We expected that natal females would be unlikely to solicit matings with adult males if they were 336motivated to avoid inbreeding. However, for those copulations with one clear initiator, just over 337 half were initiated by the female $(54.9 \% \pm 0.1$ S.E., 10 females $)$. Females varied greatly in the 338percentage of copulations they initiated $(7-77 \%, \mathrm{~N}=10)$, but there was no significant difference 339between natal females and immigrant females in this measure (Mann-Whitney $\mathrm{U}$ test, $\mathrm{z}=-0.801$, $\left.340 \mathrm{~N}_{\mathrm{I}}=5, \mathrm{~N}_{\mathrm{N}}=5, \mathrm{p}=0.49\right)$.

341

342Similarly, we expected that if natal females were avoiding inbreeding, they would differ from 343immigrants in the distribution of their matings among male partners, avoiding known kin or 344 males of the same age cohort. We calculated regressions of number of matings (log345transformed) versus the percentage of available partners mated. The slopes of these regressions 346did not differ for natal and immigrant females $(t=0.711, d f=10, p=0.49$, Figure $2 a)$.

347Similarly, when we compared the number of matings with the variance in copulation frequency 348across partners, we found no significant difference between slopes for natal and immigrant 349females $(t=-1.718, d f=10, p=0.12$, Figure $2 b)$. Thus, there was no evidence that natal females 350consistently avoided mating with certain partners.

352There was only one female who had known adult male kin, two elder brothers, in the group. This 353was LR, the female who remained to breed in her natal community. She mated with her brothers 
354at rates of 0.06 and 0.05 copulations/hour of maximal swelling, which is similar to the median 355rate of 0.05 copulations/hour (range 0.03-0.13) for other adult partners.

\section{6}

\section{Association Patterns}

358As expected, adolescence was associated with decreased association of a female with her mother 359and increased association with adolescent and adult males. For the 5 natal females with living 360mothers and association data through the time of emigration, there tended to be a marked 361decrease in maternal association in the 1-2 years prior to dispersal (Figure 3).

362There were substantial differences in association indices of adolescent females with various age363sex classes (Figure 4). Adolescent females associated most often with adolescent and adult 364males and least often with juvenile males and adult females (Friedman, $\mathrm{N}=20 ; \mathrm{X}^{2}=60.3, \mathrm{df}=5$, $365 \mathrm{p}<0.001)$. Association patterns of natal females and immigrants were similarly distributed across 366age-sex classes (Friedman, $N_{N}=12 ; X^{2}=37.0, d f=5, p<0.001 ; N_{I}=8 ; X^{2}=27.9, d f=5, p<0.001$ ), 367except that immigrant females associated significantly more frequently with adolescent and adult 368males than did natal females (Mann-Whitney $U, N_{N}=12, N_{I}=8 Z=-2.006, p=0.047 ; N_{N}=12, N_{I}$ $369=8, \mathrm{Z}=-2.237, \mathrm{p}=0.025)$

371There was a non-significant trend for females who dispersed at a younger-than-average age 372(N=4) to have lower association indices across age-sex classes, particularly with adolescent and 373adult males, than late dispersing females $(\mathrm{N}=4)$ (Figure 5a). In line with this tendency, LR (who 374stayed to breed in her natal group) had association indices similar to females who emigrated late. 375Early emigrating females also demonstrated a trend toward lower association indices with their 376mothers than females who emigrated late or not at all (data standardized by age; Mann Whitney $377 \mathrm{U}$ test $\mathrm{z}=-1.879 \mathrm{p}=0.06$; Figure $5 \mathrm{~b}$ ). 


\section{Physiological Stress}

380Urinary cortisol levels were remarkably stable during adolescence. There was a marginally 381 significant trend toward decreasing cortisol with age between 5 and 12 years $\left(\mathrm{R}^{2}=0.51, \mathrm{df}=7\right.$ 382age groups, $\mathrm{N}=3-9$ females/year, $\mathrm{p}=0.05$ ). However, this actually represented a very low range 383of variation (time-adjusted residuals: -25.7 to -58.6 ), equivalent to 0.2 standard deviations of the 384mean for all Kanyawara females. Because females matured on different reproductive schedules, 385an analysis based on chronological age might mask underlying variation with regard to 386gynecological age. However, cortisol profiles aligned relative to gynecological age also showed 387 little variation $\left(R^{2}=0.30, d f=5, N=4-5\right.$ females per year, $p=0.26$. Figure $\left.6 a\right)$. In general, the 388time-adjusted cortisol residuals for natal adolescent females were negative, indicating that stress 389hormone levels were lower than average for immigrant and adult Kanyawara females (c.f., 390Kahlenberg et al., 2008b).

391

392To examine whether social stress could act as a trigger for dispersal, we examined cortisol titers 393of females aligned relative to the time of emigration. We found no indication that either an 394abrupt or gradual increase in cortisol preceded emigration $\left(\mathrm{R}^{2}=0.55, \mathrm{df}=5, \mathrm{~N}=2-5\right.$ females per 395year, $\mathrm{p}=0.09$; Figure $6 \mathrm{~b}$ ). Within the constraints of our small sample size, we also asked 396whether females with relatively high cortisol during adolescence were more likely to disperse 397early. There was no evidence for this. In fact, females who emigrated before the average age 398had slightly lower cortisol titers on average $(-95.0 \pm 18.2 \mathrm{SE}, \mathrm{N}=3)$ than females who emigrated 399late or not at all $(-51.2 \pm 23.1, \mathrm{~N}=4)$. Similarly, females who emigrated soon after sexual 400cycling had slightly lower cortisol levels $(-85.8 \pm 27.2, \mathrm{~N}=2)$ than females who had not 401 emigrated within a year of cycling $(-63.6 \pm 21.8, \mathrm{~N}=5)$.

\section{Ecological Variation}


404We predicted that changes in energy availability might affect the timing of dispersal if females 405choose times of positive energy balance to undertake the potential costs of emigration or, 406alternatively, if resource pressure leads them to look elsewhere for new foraging grounds. 407Among transfer events with available dietary data, there was a tendency for both emigrations 408(6/8) and immigrations (5/7) to occur in months of above average fruit consumption by 409Kanyawara chimpanzees (\% fruit composition in diet, reference data from Emery Thompson \& 410Wrangham, 2008). However, fruit consumption in these months was not significantly different 411 from the set of months in which no transfer event occurred $(69.3 \% \pm 4.0$ SE vs. $64.8 \% \pm 1.4$, 412Mann-Whitney $\mathrm{U}, \mathrm{z}=-0.937, \mathrm{NT}=15, \mathrm{~N} 0=154, \mathrm{p}=0.35)$. Nevertheless, two additional 413findings support the hypothesis that energetic condition impacts emigration timing. First, there 414was a strong negative correlation between latency to emigrate (in months) and average fruit 415 consumption in the three month period leading up to and including the month of first maximal 416sexual swelling (Figure $7 \mathrm{a}, \mathrm{rs}=-0.75, \mathrm{~N}=8, \mathrm{p}=0.031$ ). Three females that matured during 417periods of above average fruit consumption emigrated within 2 months. Second, among the 418remaining five females with delayed dispersal, emigration coincided with periods when fruit 419consumption in Kanyawara increased significantly (Figure 7b, rs $=0.829, \mathrm{~N}=6$ months, $\mathrm{p}=$ 4200.042). Because our dietary measures do not incorporate individual differences in feeding 421behavior, a larger sample and more sensitive measures of individual energetic condition are 422needed to confirm this finding.

423

\section{DISCUSSION}

\section{5}

426At Kanyawara, we observed considerable variation in female dispersal behavior. This is 427consistent with observations at other chimpanzee study sites (Pusey, 1979; Nishida et al., 2003). 428We thus examined several hypotheses for proximate mechanisms affecting female dispersal. 
430We expected that, regardless of the ultimate reason for female dispersal in chimpanzees, 431 increased stress might be a proximate mechanism associated with this event. Stress could be 432hypothesized to result from decreased association with the mother, greater involvement in 433feeding competition and the need to establish a feeding range, or as a response to new mating 434attention from males. Elevated cortisol might also be expected from increased ranging resulting 435 from females travelling more with males and less with mothers. We were surprised to find that 436both before and after sexual cycling began, female adolescents showed very low and stable 437levels of urinary cortisol. We found no evidence that increased physiological stress either 438preceded dispersal or determined which females dispersed quickly. In theory changes in body 439size might mask increases in cortisol levels, because of the use of creatinine to correct for urinary 440concentration. However, such masking seems unlikely because a significant cortisol elevation 441was observed in immigrants, relative to same-aged natal females, corresponding to high levels of 442aggression (Kahlenberg et al. 2008b). Although it is possible that abrupt rises in stress levels 443influenced dispersal without being captured in our sample, we found no evidence that negative 444aspects of the social environment triggered emigration. Our results therefore contrast with the 445patterns of coerced emigration in some primates (Pusey \& Packer 1987) or elevated 446glucocorticoids in dispersing birds (Silverin 1997). Our cortisol data support the hypothesis that, 447at least over the short-term, the relative costs of dispersal are low.

\section{8}

449Female reproductive maturation did not reliably predict emigration. Some females emigrated 450immediately after menarche, some did so years later, and one stayed to breed in the natal 451 community. The "swelling passport" hypothesis predicts that females use their attractiveness as 452a tool to integrate into a new community (Pusey, 1979; Nishida, 1979). Males are expected to be 453welcoming to new mates, as evidenced by their low rates of aggression to immigrant females as 
454well as policing aggression directed at immigrants by resident females (Townsend et al., 2007; 455Kahlenberg et al., 2008b). In support of the passport hypothesis, females were generally cycling 456at the time of emigration. However, contrary to the hypothesis, at least two females left 457Kanyawara without having shown signs of swelling. It is possible that these females left 458immediately upon experiencing their first swelling, or had one by the time they contacted a new 459community, but this seems unlikely given that one had never shown even partial tumescence, and 460the other had shown only slight signs of swelling the day before her disappearance. 461Additionally, copulation rates and latency to first copulations do not support a strong attraction 462of Kanyawara males to immigrants. This is particularly unexpected because, assuming that 463immigrants followed similar growth trajectories as Kanyawara females, immigrant females 464should have been both older and more reproductively mature than natal adolescents, having 465experienced nearly 1 year of cycling on average before dispersal. These patterns at Kanyawara 466support a general link between sexual attractivity and dispersal, but it appears that swellings are 467not a prerequisite for acceptance into a new group, and males do not show strong mating interest 468in new cycling immigrants.

469

470We found little support for the hypothesis that inbreeding avoidance was a proximate 471determinant of female dispersal. First, prior to leaving the community natal females reduced 472their association time with their mothers and increased association time with potential sexual 473partners (see also Pusey 1990). Second, most Kanyawara females mated within the community 474before emigrating, some for well over 1 year. Third, natal females usually copulated with adult 475male community members on their first maximal swelling cycle. Fourth, there was only a small 476difference between the copulation rates of immigrants and future emigrants, and the female who 477did not emigrate maintained the highest copulation rates. Fifth, the female who did not emigrate 478had two known maternal brothers in the community and was observed mating with them. Sixth, 
479females initiated the majority of their copulations, and natal females were no less likely to do so 480than immigrants. Finally, given the high level of reproductive skew in chimpanzees (Constable 481et al. 2001; Boesch et al., 2006) many of the males that natal females mate with are likely to 482share paternally related genes. However, there was no significant difference in the number of, or 483variance among, sexual partners for natal and immigrant females, suggesting that natal females 484did not display strong aversion to certain partners or were ineffective at exerting these 485preferences. This is consistent with other primate studies, including of Gombe chimpanzees, in 486which natal adolescent females are highly proceptive toward adult males (Rasmussen, 1983; 487Goodall, 1986; Perry \& Manson, 1995), with males often showing relatively little interest in 488return (Pusey, 1978; Wrangham, 2000; Muller et al., 2007). These findings do not imply that 489inbreeding avoidance has been unimportant in the evolution of sex-biased dispersal in this 490species. Rather, they suggest that proximate dispersal decisions are not predicated on a female's 491relative risk of mating with potential relatives.

492

493We found two patterns that suggest plausible proximate models for variation in dispersal 494behavior. First, dispersal was associated with dietary quality, such that females experiencing 495conditions of high fruit consumption emigrated soon after menarche and others emigrated during 496periods of increasing fruit consumption. This may explain disparities in emigration timing, if 497 females wait until they have sufficient energy reserves to afford the high costs of dispersal, 498which could include long travel distances, lack of knowledge about new foraging areas, 499increased feeding competition, and aggression by resident females in the new community, and 500time spent in more than one community. However, it is possible that the emigration patterns we 501 observed were directly related not to dietary quality, but to a correlated variable such as the 502changing size or composition of social parties (Chapman et al., 1994; Hashimoto et al., 2003; 503Emery Thompson \& Wrangham, 2006) or an increase in fecundity or the presence of other 
504estrous females (Anderson et al., 2006; Emery Thompson \& Wrangham, 2008). While we found 505a strong significant pattern, we hope in the future to corroborate these data with a more sensitive 506measure of individual energetic condition (Emery Thompson et al., 2009).

507

508Second, there was a trend for decreasing levels of association across all age/sex classes for 509females who emigrated early versus those who emigrated later or not at all. Females who retain 510longer or stronger relationships with natal group members, particularly their mothers, may delay 511dispersal. These females might be in a better position to exploit high-quality core foraging areas 512(e.g., Emery Thompson et al., 2007a; Kahlenberg et al., 2008a), which could affect their 513emigration decisions. However, core area location could also indirectly affect their rates of 514 contact with other group members or bias their ease of observation in larger or smaller groups. 515

516Our hypotheses, given the available data, are not exhaustive. Here, we briefly discuss some 517alternatives that warrant future examination. Reproductive success in female chimpanzees is 518critically sensitive to seasonal and inter-individual variation in the availability of high quality 519food resources (Emery Thompson et al., 2007b; Emery Thompson \& Wrangham, 2008), and 520relative social status is an important predictor of resource access (Pusey et al., 1997; Murray et 521al., 2006; Kahlenberg et al., 2008a). It appears that a key challenge during adolescence, perhaps 522one of the most critical in a female chimpanzee's life, is establishing long-term access to a core 523 foraging area, the best of which will be subject to intense competition (Williams et al., 2002; 524Townsend et al., 2007; Kahlenberg et al., 2008a,b; Pusey, 1980; Pusey et al., 2008). In 525Kanyawara, in particular, females occupying lower quality foraging areas have significant 526deficits in reproductive rates and offspring survivorship (Emery Thompson et al., 2007a). 527Therefore, the dispersal decisions of individual females might be expected to hinge on the 528quality of foraging opportunities and the degree of female competition in the natal group versus 
529nearby communities (Pusey et al., 1997). This hypothesis is difficult to examine without detailed 530knowledge of neighboring chimpanzee groups and habitats. Furthermore, the reproductive 531advantage of dispersing vs. remaining may differ across sites, given that studies in different 532chimpanzee communities suggest that the age at first birth may be comparatively delayed 533(Boesch \& Boesch-Achermann, 2000) or advanced (Nishida et al., 2003) in natal vs. dispersing 534individuals, and that in some populations a high proportion of natal females fails to disperse 535(Pusey et al. 1997). Nonetheless, the importance of this decision may explain observations like 536those at Gombe, where nulliparous females sometimes spend time visiting one or more 537neighboring communities before returning temporarily or permanently to their natal group 538(Pusey, 1979). Without access to habituated neighboring communities, we cannot be certain 539how frequently this happens at Kanyawara, but unusual periods of absence by adolescent females 540make it likely. Our sample of adolescent females, however, is overwhelmingly comprised of the 541daughters of females in the high-quality foraging ranges, thus we cannot easily explain 542disparities in dispersal behaviors by social status alone. It is interesting that LR, who did not 543emigrate, was the daughter of the alpha female, was high-ranking compared to other nulliparous 544females, and inherited her mother's high-quality foraging range (Kahlenberg et al., 2008a). 545

546Relative morphological (skeletal) maturation could also be an important variable influencing 547dispersal timing, if it influences female competitive success and access to high-quality feeding 548areas in the new community. Alternately, as adolescent subfecundity in chimpanzees is lengthy 549and highly variable (1.2 - 4.1 years at Mahale, Nishida et al., 2003; $0.7-4.9$ years at Gombe, 550Wallis, 1997), differences in the development of ovulatory function among females may better 551predict timing of dispersal. An appropriate test of this hypothesis would incorporate measures of 552ovarian hormone production in both emigrants and immigrants. 
554This and other hypotheses arise from and highlight two significant questions. First, why do 555 females cycle and mate in their natal community prior to emigration? Because ovulatory function 556takes time to develop in anthropoids (Lunenfield et al., 1978; Resko et al., 1982; Zehr et al., 5572004), an extended period of subfecundity permits females to cycle several times prior to 558emigration with little inbreeding risk, providing opportunity to obtain social, sexual and foraging 559knowledge in a context when they are among familiar individuals but semi-independent of their 560mothers (Shepher, 1983; Strier, 1997). A second question is why females experience such a long 561delay between dispersal and reproduction. This may simply reflect the long duration of 562adolescent subfecundity, though our data and those from Mahale (Nishida et al., 2003) suggest 563that immigrants have delays in reproduction relative to natal females. Similarly, even females 564who changed foraging areas within the community at Gombe had disrupted reproduction 565(Williams et al., 2002). Such a delay could occur as a consequence of social and energetic 566stresses of the dispersal process. Reproductive delay would also diminish infanticide risk 567through increasing the probably of paternity within the new community's male cohort by 568establishing a mating history and forging social bonds.

569

570While there has been considerable theoretical inquiry regarding the evolution of sex-biased 571dispersal, and models have been proposed to explain the advantages of male versus female 572dispersal in various species, few primate studies have examined the proximate mechanisms 573influencing dispersal. For chimpanzees, in which dispersal is almost exclusively by females, 574dispersal is not strictly predicted by the physiological events of puberty nor by stress in the natal 575community. Our data from Kanyawara suggests that individual variation in sociality, temporal 576variation in energy availability, and perhaps subtle variation in developmental trajectories, play 577roles in female decisions to seek new communities. 


\section{Acknowledgements}

580We thank the Uganda Wildlife Authority, Uganda National Council for Science and Technology, 581Makerere University Biological Field Station, and J. Kasenene for research permissions and 582local support. Daily chimpanzee observations were conducted by field assistants F. Mugurusi, P. 583Tuhairwe, the late D. Muhangyi, the late J. Barwogeza, the late C. Muruuli, C. Katongole, 584Sunday John, J. Kyomuhando, S. Musana, J. Musunguzi, D. Sebugwawo and C. Itumba. We 585thank field managers C. Hooven, M.Wilson, K. Pieta, K. Duffy, A. Houle, and E. Otali. 586Additional thanks to J.D. Polk and C. Rasmussen for assistance in preparation of the manuscript, 587J. Moore, K. Jack, and one anonymous reviewer for valuable comments and suggestions, and K. 588Jack and L. Isbell for inviting us to contribute to this special issue. Kanyawara research was 589funded by the U.S. National Science Foundation (grant no. 0416125), the L.S.B. Leakey 590Foundation, and the Wenner-Gren Foundation.

591

\section{Bibliography}

593

594Alberts, S.C. \& Altmann, J. (1995a). Balancing costs and opportunities: Dispersal in male 595 baboons. - Amer. Nat. 145: 279-306.

596

597Alberts, S.C. \& Altmann, J. (1995b). Preparation and activation: Determinants of age at 598 reproductive maturity in male baboons. - Behav. Ecol. Sociobiol. 36: 397-406.

600Anderson, D.P., Nordheim, E.V., Boesch, C. (2006). Environmental factors influencing the

601 seasonality of estrus in chimpanzees. - Primates 47: 43-50.

602

603Belthoff, J.R. \& Dufty Jr., A.M. (1998). Corticosterone, body condition and locomotor activity: a 604 model for dispersal in screech-owls. - Anim. Behav. 55: 405-415.

605

606Boesch, C. \& Boesch-Achermann, H. (2000). The chimpanzees of the Taï Forest: Behavioural 607 ecology and evolution. - Oxford University Press, Oxford.

609Boesch, C., Kohou, G., Néné, H. \& Vigilant, L. (2006). Male competition and paternity in wild 610 chimpanzees of the Taï Forest. - Amer. J. Phys. Anthro. 130: 103-115. 
615Cairns, S.J. \& Schwager, S.J. (1987). A comparison of association indices. - Anim. Behav. 35:

$616 \quad 1454-1469$.

617

618Chapman, C.A. \& Wrangham, R.W. (1993). Range use of the chimpanzees of Kibale:

619 Implications for the evolution of chimpanzee social organization. - Am. J. Primatol. 31:

$620263-273$.

621

622Chapman, C.A., White, F.J., Wrangham, R.W. (1994). Party size in chimpanzees and bonobos: a

623 reevaluation of theory based on two similarly forested sites. In: Chimpanzee cultures

624 (Wrangham, R.W., McGrew, W.C., de Waal, F.B. \& Heltne, P., eds). Harvard University

625 Press, Cambridge, p. 41-58.

626

627Constable, J.L., Ashley, M.V., Goodall, J. \& Pusey, A.E. (2001). Noninvasive paternity

628 assignment in Gombe chimpanzees. - Mol. Ecol. 10: 1279-1300.

629

630Cremer, S. \& Heinze, J. (2003). Stress grows wings. Environmental induction of winged

631 dispersal males in Cardiocondyla ants. - Curr. Biol. 13: 219-223.

632

633Crockett, C.M., \& Pope, T.R. (1993). Consequences of sex differences in dispersal for juvenile

634 red howler monkeys. - In: Juvenile primates: Life history, development, and behavior

635 (Pereira, M.E. \& Fairbanks, L.A. eds). Oxford University Press, Oxford, p. 454-565.

636

637Dahl, J.F., Nadler, R.D. \& Collins, D.C. (1991). Monitoring the ovarian cycles of Pan

638 troglodytes and P. paniscus: a comparative approach. - Am. J. Primatol. 24: 195-209.

639

640Emery Thompson, M. (2005) Reproductive endocrinology of wild female chimpanzees (Pan

641 troglodytes schweinfurthii): Methodological considerations and the role of hormones in sex

642 and conception. - Am. J. of Primat. 67: 137-158.

643

644Emery Thompson, M., Kahlenberg, S.M., Gilby, I.C. \& Wrangham, R.W. (2007a). Core area

645 quality is associated with variance in reproductive success in chimpanzees at Kanyawara,

646 Kibale National Park. - Anim. Behav. 73: 501-512.

647

648Emery Thompson, M., Jones, J.H., Pusey, A.E., Brewer-Marsden, S., Goodall, J., Marsden, D.,

649 Matsuzawa, T., Nishida, T., Reynolds, V., Sugiyama, Y. \& Wrangham, R.W. (2007b). Aging

650 and fertility patterns in wild chimpanzees provide insights into the evolution of menopause. -

651 Curr. Bio. 17: 2150-2156.

652

653Emery Thompson, M. \& Wrangham, RW. (2008). Diet and reproductive function in wild female

654 chimpanzees (Pan troglodytes schweinfurthii) at Kibale National Park, Uganda. - Am. J. of

655 Phys.Anthro. 135: 171-181.

656

657Emery Thompson, M. \& Wrangham, R.W. (2006). Comparison of sex differences in

658 gregariousness in fission-fusion species: reducing bias by standardizing for party size. - In:

659 Primates of Western Uganda (Newton-Fisher, N.E., Notman, H., Reynolds, V., Paterson, J.,

660 eds). Springer, New York, p. 209-226.

661

662Emery Thompson, M., Muller, M., Wrangham, R, Lwanga, J. \& Potts, K. (2009). Urinary C-

663 peptide tracks seasonal and individual variation in energy balance in wild chimpanzees. -

664 Hormon. \& Behav. 55: tba. 
666Emlen, S.T. \& Oring, L.W. (1977). Ecology, sexual selection, and the evolution of mating

667 systems. - Science 197: 215-223.

668

669Fedigan, L.M. \& Jack, K. (2004). The demographic and reproductive context of male

670 replacements in Cebus capucinus: How, when and why do male white-faced capuchins

671 take over groups? - Behav. 141: 755-775.

672

673Ginsberg, J.R. \& Young, T.P. (1992). Measuring association between individuals or groups in

674 behavioural studies. - Anim. Behav. 44: 377-379.

675

676Goodall, J. (1986). The chimpanzees of Gombe: Patterns of behavior. - Belknap Press,

677 Cambridge.

678

679Hashimoto, C., Suzuki, S., Takenoshita, Y., Yamagiwa, J., Basabose, A.K., Furuichi, T. (2003).

680 How fruit abundance affects the chimpanzee party size: a comparison between four study

681 sites. - Primates 44: 77-81.

682

683Isabirye-Basuta, G. (1988). Food competition among individuals in a free-ranging chimpanzee

684 community in Kibale Forest, Uganda. - Behav. 105: 135-147.

685

686Isabirye-Basuta, G. (1989). Feeding ecology of chimpanzees in the Kibale Forest, Uganda. - In:

687 Understanding chimpanzees (Heltne, P.N. \& Marquardt, L., eds). Harvard University Press,

688 Cambridge: p. 116-127.

689

690Jack, K. \& Fedigan, L.M. (2004a). Male dispersal patterns in white-faced capuchins (Cebus

691 capucinus) Part 1: Patterns and causes of natal emigration. - Anim. Behav. 67(4):761-769.

692

693Jack K and Fedigan LM. 2004b. Male dispersal patterns in white-faced capuchins, Cebus

694 capucinus Part 2: Patterns and causes of secondary dispersal. - Anim. Behav. 67(4):771-782.

695

696Jolly, A., Gustafson, H., Oliver, W.L.R. \& O’Connor, S. M. (1982).Propithecus verreauxi

697 population and ranging at Berenty, Madagascar, 1975 and 1980.- Folia primatol. 39: 124-

698144.

699

700Kahlenberg, S.M., Emery Thompson, M., Wrangham, R.W. (2008a). Female competition over

701 core areas in Pan troglodytes schweinfurthii, Kibale National Park, Uganda. - Int. J.

702 Primatol. 29: 931-947.

703

704Kahlenberg, S.M., Emery Thompson, M., Muller, M.N. \& Wrangham, R.W. (2008b).

705 Immigration costs for female chimpanzees and male protection as an immigrant

706 counterstrategy to intrasexual aggression. - Anim. Behav. 76: 1497-1509.

707

708Lunenfeld, F., Kraiem, Z., Eshkol, A. \& Werner-Zodrow, I. (1978). The ovary learns to ovulate.

709 - J. Biosocial Sci. Supp. 5: 43-62.

710

711Lurz, P.W.W., Garson, P.J. \& Wauters, L.A. (1997). Effects of temporal and spatial variation in 712 habitat quality on red squirrel dispersal behavior. Anim. Behav. 54: 427-435.

713 
714Melnick, D. \& Pearl, M. (1987). Cercopithecines in multimale groups: Genetic diversity and

715 population structure. - In: Primate Societies. (Smuts, B.B., Cheney, D.L., Seyfarth, R.M.,

716 Wrangham, R.W. \& Struhsaker, T.T., eds). University of Chicago, Chicago, p. 121-134.

717

718Moore, J. (1984). Female transfer in primates. - Int. J. Primatol. 5: 537-589.

719

720Moore, J. \& Ali, R. (1984). Are dispersal and inbreeding avoidance related? - Anim. Behav. 32:

721 94-112.

722

723Muller, M.N. \& Lipson, S.F. (2003). Diurnal patterns of urinary steroid excretion in wild

724 chimpanzees. - Am. J. Primatol. 60:161-166.

725

726Muller, M.N. \& Wrangham, R.W. (2004a). Dominance, aggression and testosterone in wild

727 chimpanzees: a test of the 'challenge hypotheses'. - Anim. Behav. 67:113-123.

728

729Muller, M.N. \& Wrangham, R.W. (2004b). Dominance, cortisol and stress in wild chimpanzees

730 (Pan troglodytes schweinfurthii). - Behav. Ecol. and Sociobiol. 55: 332-340.

731

732Muller, M.N., Kahlenberg, S.K., Emery Thompson, M. \& Wrangham, R.W. (2007). Male

733 coercion and the costs of promiscuous mating in chimpanzees. - Proc. Roy. Soc. B: Bio. Sci.

734 274: 1009-1014.

735

736Murray, C.M., Eberly, L.E. \& Pusey, A.E. (2006). Foraging strategies as a function of season

737 and rank among wild female chimpanzees. (Pan troglodytes). - Behav. Ecol. 17:1020-1028.

738

739Nishida, T. (1979). The social structure of chimpanzees of the Mahale Mountains. - In: The

740 great apes (Hamburg, D.A. \& McCown, E.R., eds). Benjamin/Cummings, Menlo Park.

742Nishida, T., Corp, N., Hamai, M., Hasegawa, T., Hiraiwa-Hasegawa, M., Hosaka, K., Hunt,

743 K.D., Itoh, N., Kawanaka, K., Matsumoto-Oda, A., Mitani, J.C., Nakamura, M., Norikoshi,

744 K., Sakamaki, T., Turner, L., Uehara, S. \& Zamma, K. (2003). Demography, female life

745 history, and reproductive profiles among the chimpanzees of Mahale. - Am. J. Primatol. 59:

746 99-121.

747

748Nunes, S., Duniec, T.R., Schweppe, S.A \& Holekamp, K.E. (1999). Energetic and endocrine

749 mediation of natal dispersal behavior in Belding's ground squirrels. Hormon. \& Behav. 335 :

$750 \quad 113-124$.

751Perry, S. \& Manson, J.H. (1995). A comparison of the mating behavior of adolescent and adult

752 female rhesus macaques (Macaca mulatta). - Primates. 36: 27-39.

753Pusey, A.E. (1978). The physical and social development. of wild adolescent chimpanzees (Pan 754 troglodytes schweinfurthii). Ph.D., Stanford University.

755

756Pusey, A.E. (1979). Inter-community transfer of chimpanzees in Gombe National Park. - In: The

757 great apes. (Hamburg, D. \& McCown, E., eds). Benjamin/Cummings, Menlo Park, p. 465-

758479.

759

760Pusey, A.E. (1980). Inbreeding avoidance in chimpanzees. -Anim. Behav. 28: 543-552.

761 
762Pusey, A.E. \& Packer, C. (1987). Dispersal and philopatry. - In: Primate Societies, (Smuts, B.B.,

763 Cheney, D.L., Seyfarth, R.M., Wrangham, R.W. \& Struhsaker, T.T., eds). University of

764 Chicago Press, Chicago, p. 250-266.

765

766Pusey, A.E. (1990). Behavioural changes at adolescence in chimpanzees. - Behav. 115: 203-246.

767

768Pusey, A.E., Williams, J. \& Goodall, J. (1997). The influence of dominance rank on the

769 reproductive success of female chimpanzees. - Science 277: 828-831.

770

771Pusey A., Murray C., Wallauer W., Wilson M., Wroblewski E. \& Goodall J. (2008). Severe

772 aggression among female chimpanzees at Gombe National Park, Tanzania. -Int. J. Primatol.

773 29: 949-973.

774

775Rasmussen, K.L.R. (1983). Age-related variation in interactions of yellow baboons. - In: Primate

776 social relationships: An integrated approach. (Hinde, R.A., ed.). Blackwell, Oxford, p. 47-52.

777

778Resko, J.A., Goy, R.W., Robinson, J.A. \& Norman, R.L. (1982). The pubescent rhesus monkey -

779 Some characteristics of the menstrual cycle. - Biol. Reprod. 27:354-361.

780

781Shimizu, K., Douke, C., Fujita, S., Matsuzawa, T., Tomonaga, M., Tanaka, M., Matsubayashi, K. 782 \& Hayashi, M. (2003). Urinary steroids, FSH and CG measurements for monitoring the

783 ovarian cycle and pregnancy in the chimpanzee. - J. Med. Primatol. 32: 15-22.

784

785Shepher, J. (1983). Incest: A biosocial view. - Academic, New York.

786

787Silk, J.B., Alberts, S.C; \& Altmann, J. (2003). Social bonds of female baboons enhance infant

788 survival. - Science 302:1331-1334.

789

790Silverin, B. (1997). The stress response and autumn dispersal behaviour in willow tits. - Anim.

791 Behav. 53: 451-459.

792

793Smuts, B.B. (1993). Male aggression and sexual coercion of females in nonhuman primates and

794 other mammals: evidence and theoretical implications. - Advan. Stud. Behav. 22: 1-63.

795

796Strier, K.B. (1997). Mate preferences in wild muriqui monkeys (Brachyteles arachnoides):

797 reproductive and social correlates. - Folia Primatol. 68: 120-133.

798

799Stumpf, R.M. (2007). Chimpanzees and bonobos: Diversity within and between species. - In:

800 Primates in Perspective (Campbell, C., Fuentes, A., MacKinnon, K., Panger, M. \& Bearder,

801 S., eds). Oxford University Press, Oxford, p. 321-344.

802

803Townsend, S.W., Slocombe, K.E., Emery Thompson, M. \& Zuberbühler, K. (2007). Female-led 804 infanticide in wild chimpanzees. - Curr. Biol. 17: 365-366.

805

806Trivers, R.L. (1972). Parental investment and sexual selection. - In: Sexual selection and the

807 descent of man. (Campbell B., ed.). Aldine-Atherton, Chicago, p. 136-79.

808

809Wallis J. (1997). A survey of reproductive parameters in the free-ranging chimpanzees of Gombe 810 National Park. - J. Reprod. Fertil. 109: 297-307. 
812Watts, DP. (2007). Effects of male group size, parity, and cycle stage on female chimpanzee

813 copulation rates at Ngogo, Kibale National Park, Uganda. - Primates 48: 222-231.

814

815Whitehead, H. \& Dufault, S. (1999). Techniques for analyzing vertebrate social structure using

816 identified individuals: review and recommendations. - Adv. Stud. Behav. 28: 33-74.

817

818Widholm, O. \& Kantero, R. (1971). A statistical analysis of the menstrual patterns of 8,000

819 Finnish girls and their mothers. - Acta Obstet Gynecol Scand. 14:1-36.

820

821Williams, J.M., Pusey, A.E., Carlis, J.V., Farm, B.P. \& Goodall, J. (2002). Female competition

822 and male territorial behaviour influence female chimpanzees' ranging patterns. - Anim.

823 Behav. 63: 347-360.

824

825Williams, J.M., Oehlert, G.W., Carlis, J.V. \& Pusey, A.E. (2004). Why do male chimpanzees

826 defend a group range? - Anim. Behav. 68: 523-532.

827

828Wrangham, R. (1980). An ecological model of female-bonded primate groups. - Behav. 75:

$829262-300$.

830

831Wrangham, R.W. (1987). Evolution of social structure. - In: Primate societies. (Smuts, B.B.,

832 Cheney, D.L., Seyfarth, R.M., Wrangham, R.W. \& Struhsaker, T.T., eds). University of

833 Chicago Press, Chicago, p. 282-296.

834

835Wrangham, R,W, Conklin, N,L, Chapman, C.A., Hunt, K.D. (1991). The significance of fibrous

836 foods for Kibale Forest chimpanzees. - Phil. Trans. Roy. Soc. Lond. B. 334: 171-178.

837

838Wrangham, R.W., Chapman, C.A., Clark, A.P. \& Isabirye-Basuta, G. (1996). Social ecology of

839 Kanyawara chimpanzees; Implications for understanding the costs of great ape groups. - In:

840 Great ape societies. (McGrew, W., Marchant, L.F. \& Nishida, T., eds). Cambridge University

841 Press, Cambridge, p. 45-57.

842

843Wrangham, R.W. (2000). Why are male chimpanzees more gregarious than mothers? A scramble

844 competition hypothesis. - In: Male primates (Kappeler, P., ed.). Cambridge University Press,

$845 \quad$ Cambridge, p. 248-258.

846

847Wrangham, R.W. (2002). The cost of sexual attraction: Is there a trade-off in female Pan between sex 848 appeal and received coercion? -In: Behavioural diversity in chimpanzees and bonobos (Boesch,

849 C., Hohmann, G. \& Marchant, L., eds). Cambridge University Press, Cambridge, p. 204-215.

850

851Zehr, J.L., Van Meter, P.E. and Wallen, K. (2004). Factors regulating the timing of puberty onset

852 in female rhesus monkeys (Macaca mulatta): Role of prenatal androgens, social rank, and

853 adolescent body weight, Biol. Reprod. 72, 1087-1094. 
854Table 1. Kanyawara Chimpanzee Subjects 855

\begin{tabular}{|c|c|c|c|c|c|c|}
\hline Female & $\begin{array}{l}\text { Date of } \\
\text { Birth }^{1}\end{array}$ & Immigration Status & \begin{tabular}{|l} 
Age of \\
Emigration
\end{tabular} & $\begin{array}{l}\text { Association } \\
\text { data }\end{array}$ & $\begin{array}{l}\text { Copulation } \\
\text { data }\end{array}$ & $\begin{array}{l}\text { Cortisol data } \\
\text { (N days) }\end{array}$ \\
\hline WR & $7 / 2 / 1982$ & Emigrated 1997 & 14 & $\mathrm{Y}$ & $\mathrm{N}$ & 0 \\
\hline $\mathrm{NE}$ & $7 / 2 / 1983$ & Emigrated 1999 & 16 & $\mathrm{Y}$ & $\mathrm{Y}$ & 12 \\
\hline $\mathrm{BW}^{2}$ & $7 / 2 / 1985$ & Emigrated 1997 & 12 & $\mathrm{Y}$ & $\mathrm{N}$ & 0 \\
\hline BR & $7 / 2 / 1989$ & Emigrated 2000 & 11 & $\mathrm{Y}$ & $\mathrm{Y}$ & 7 \\
\hline AS & $11 / 2 / 1990$ & Emigrated 2002 & 12 & $\mathrm{Y}$ & $\mathrm{Y}$ & 44 \\
\hline GA & $1 / 15 / 1991$ & Emigrated 2001 & 10 & $\mathrm{Y}$ & $\mathrm{N}$ & 8 \\
\hline JK & $11 / 15 / 1992$ & Emigrated 2007 & 15 & $Y$ & $\mathrm{~N}$ & 58 \\
\hline OK & $11 / 15 / 1994$ & Emigrated 2007 & 13 & $\mathrm{Y}$ & $\mathrm{Y}$ & 198 \\
\hline LR & $5 / 15 / 1989$ & $\begin{array}{l}\text { Natal, bred in } \\
\text { Kanyawara }\end{array}$ & $\mathrm{n} / \mathrm{a}$ & $\mathrm{Y}$ & $\mathrm{Y}$ & 143 \\
\hline FN & 5/30/1989 & Juvenile (died 1998) & * & Y & $\mathrm{n} / \mathrm{a}$ & 1 \\
\hline LS & 11/10/1996 & Juvenile & $* *$ & $\mathrm{Y}$ & $\mathrm{n} / \mathrm{a}$ & 67 \\
\hline $\mathrm{BU}$ & $12 / 28 / 1997$ & Juvenile & $* *$ & $\mathrm{Y}$ & $\mathrm{n} / \mathrm{a}$ & 17 \\
\hline OT & 2/13/1998 & Juvenile & $* *$ & $\mathrm{Y}$ & $\mathrm{n} / \mathrm{a}$ & 106 \\
\hline NP & $2 / 9 / 2000$ & Juvenile & $* *$ & $Y$ & $\mathrm{n} / \mathrm{a}$ & 67 \\
\hline TG & $7 / 2 / 1980$ & Immigrated 1993 & $\mathrm{n} / \mathrm{a}$ & $\mathrm{Y}$ & $\mathrm{N}$ & $\mathrm{n} / \mathrm{a}$ \\
\hline UM & 7/2/1981 & Immigrated 1995 & $\mathrm{n} / \mathrm{a}$ & $Y$ & $Y$ & $\mathrm{n} / \mathrm{a}$ \\
\hline $\mathrm{AL}$ & 7/2/1982 & Immigrated 1994 & $\mathrm{n} / \mathrm{a}$ & $\mathrm{Y}$ & $\mathrm{Y}$ & $\mathrm{n} / \mathrm{a}$ \\
\hline NL & $7 / 2 / 1982$ & Immigrated 1997 & $\mathrm{n} / \mathrm{a}$ & $\mathrm{Y}$ & $Y$ & $\mathrm{n} / \mathrm{a}$ \\
\hline WA & 7/2/1991 & Immigrated 2004 & $\mathrm{n} / \mathrm{a}$ & $Y$ & $Y$ & $\mathrm{n} / \mathrm{a}$ \\
\hline $\mathrm{HH}$ & $7 / 2 / 1992$ & Immigrated 2005 & n/a & $\mathrm{Y}$ & $\mathrm{Y}$ & $\mathrm{n} / \mathrm{a}$ \\
\hline QT & 7/2/1992 & Immigrated 2005 & $\mathrm{n} / \mathrm{a}$ & $\mathrm{Y}$ & $\mathrm{Y}$ & $\mathrm{n} / \mathrm{a}$ \\
\hline WL & 7/2/1992 & Immigrated 2005 & $\mathrm{n} / \mathrm{a}$ & $\mathrm{Y}$ & $\mathrm{Y}$ & $\mathrm{n} / \mathrm{a}$ \\
\hline
\end{tabular}

8561 Dates of birth given as July 2 are estimated to the nearest year. Others are known to within one 857 month.

8582 It is unclear whether BW was a natal female or a previous immigrant who subsequently left the 859 community.

$860 *$ Died prior to emigration; ** had not emigrated by time of publication; $\mathrm{Y}=\mathrm{yes} ; \mathrm{N}=\mathrm{No} ; \mathrm{n} / \mathrm{a}=$ 861 data type was not applicable.

862

863

864

865

866

867

868 


\section{Figure Legends}

\section{1}

872Figure 1. Copulation rates (mean \pm standard error) of adolescent females relative to their first 873maximal sexual swelling in the community.

874

875Figure 2. Sexual partner variety in immigrant and natal females: (a) proportion of adult males in 876the community mated in relation to total copulations, (b) variance in copulation frequency across 877partners. Natal females are designated by solid circles with a solid black logarithmic trend line; 878immigrant females are designated by open squares and a dotted trend line.

\section{9}

880Figure 3.Association indices between natal adolescent female chimpanzees and their mothers $881(\mathrm{~N}=5)$ decreased abruptly in the year prior to transfer, and corresponded to increased association 882indices with natal adolescent and adult males.

883

884Figure 4. Adolescent female association times with each age/sex class (box: median \pm 885interquartile range; whiskers:range). Adolescent females $(\mathrm{N}=20)$ associated significantly more 886 with adolescent and adult males and least with juvenile males and adult females. Mothers and 887maternal siblings are excluded from analyses.

888

889Figure 5a. Association indices (mean \pm standard error) for early $(\mathrm{N}=4)$, late $(\mathrm{N}=4)$ and non890transferring $(\mathrm{N}=1)$ adolescent females. (a) Early transferring females demonstrated lower 891 association indices across the majority of age/sex classes, particularly with adolescent and adult 892males, than late or non-transferring females, though these differences were not significant. (b). 893Association indices for early vs late/non-transferring females with their mothers. Data 894standardized by age.

895

896Figure 6. Longitudinal patterns of urinary cortisol in adolescent chimpanzees females (mean \pm 897standard error of individuals) aligned (a) relative to gynecological age [first maximal swelling = 8980 ], and (b) relative to time of emigration. Y-axis is set to \pm 1 standard deviation of cortisol 899 concentrations in all female samples of this population.

900

901Figure 7. Relationship between fruit consumption and emigration timing. (a) Latency to 902emigration (Y-axis) correlated negatively with fruit consumption in the 3-month window up to 903 and including the month of first maximal swelling. (b) Among females with delayed emigration 904( $>2$ months after maturity), timing of emigration was associated with increasing fruit 905consumption. Dotted lines indicate mean fruit consumption at Kanyawara from 1994-2007. 906 
907Figure 1

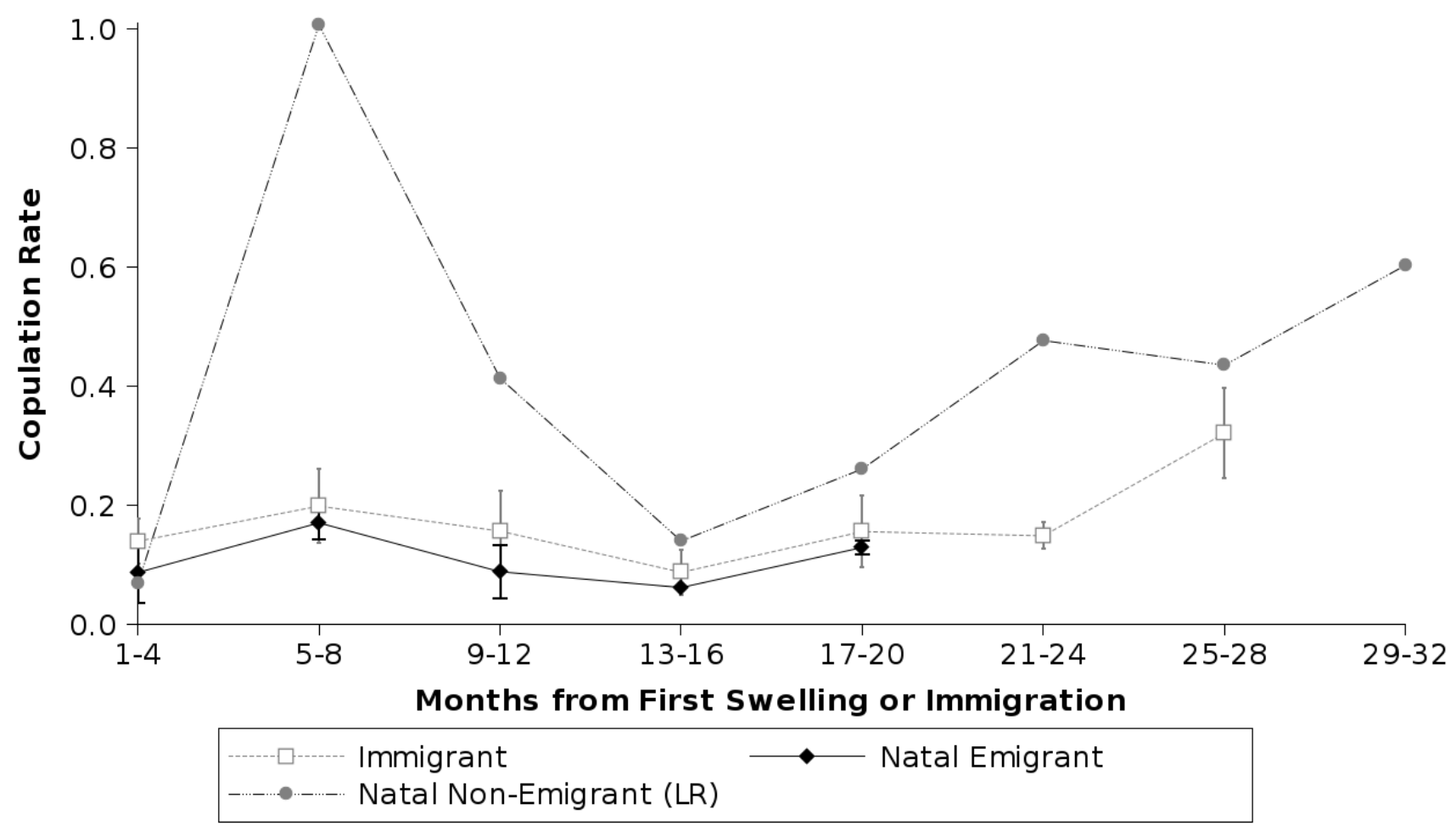


908Figure 2.

909

910(a)

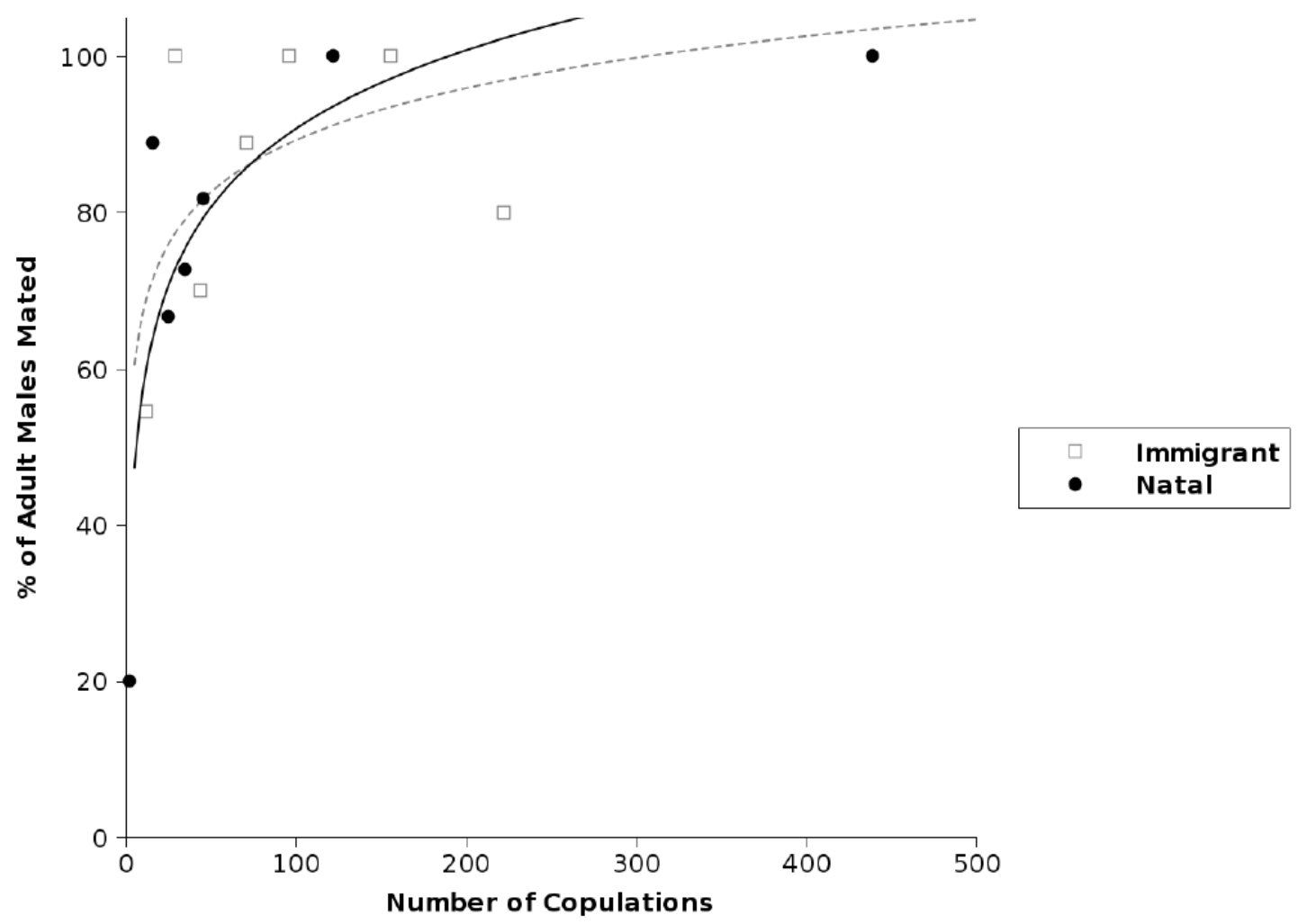

912

913

914

915

916

917

918

919

920

921

922

923

924

925

926

927

928

929

930

931

932

933

934

935

936

937

938(b)

939 


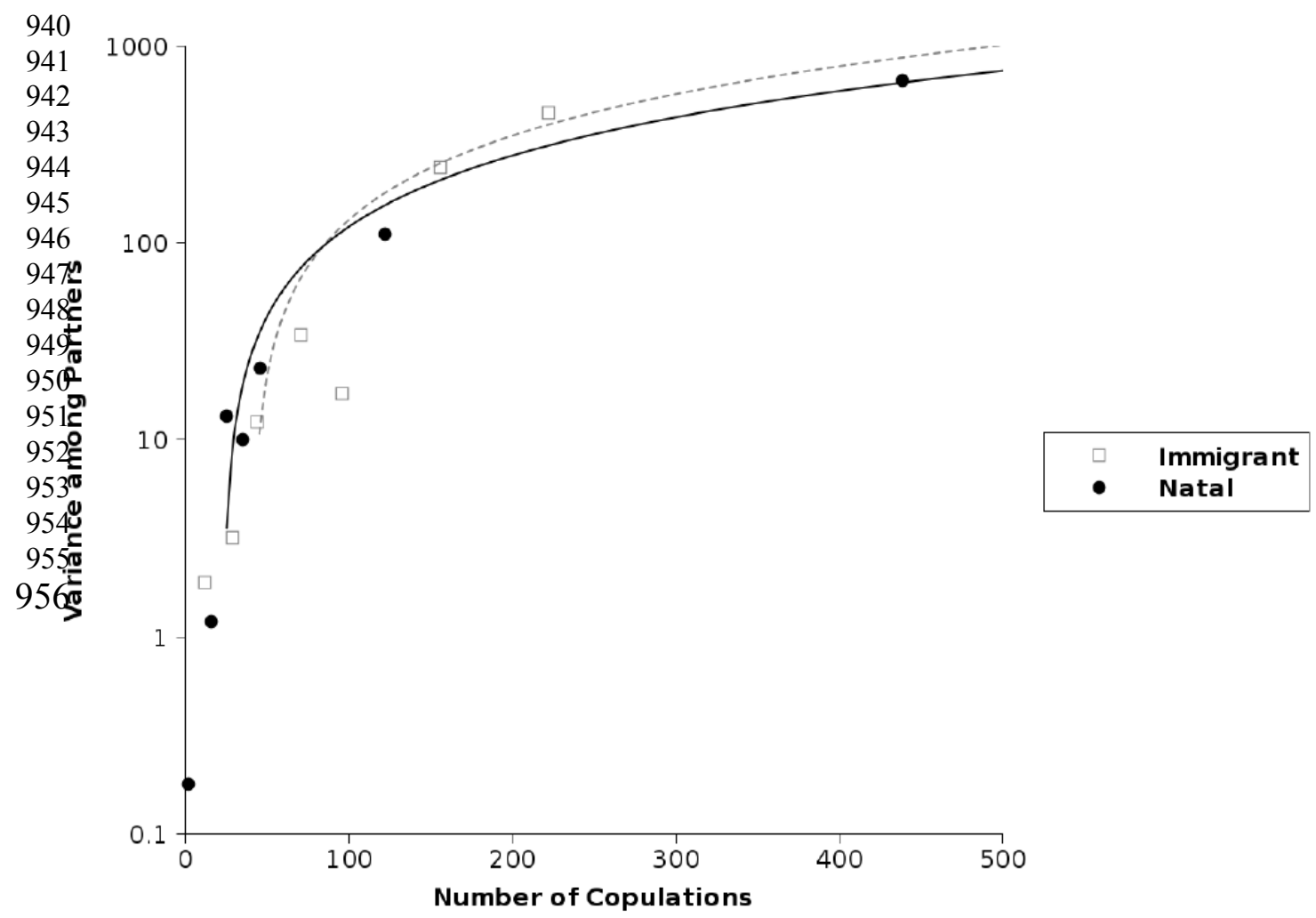


957Figure 3.

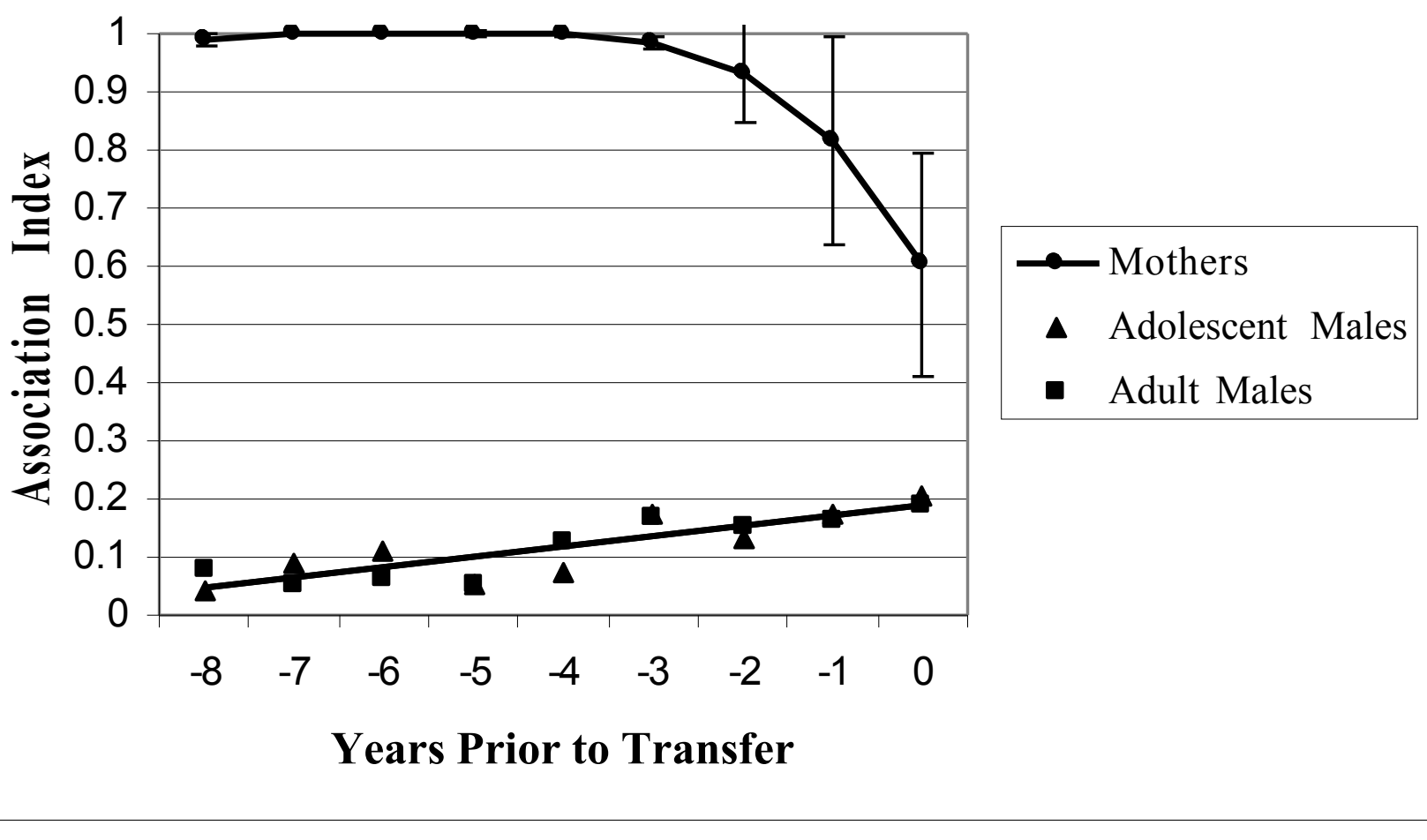

958

959Figure 4.

960

961

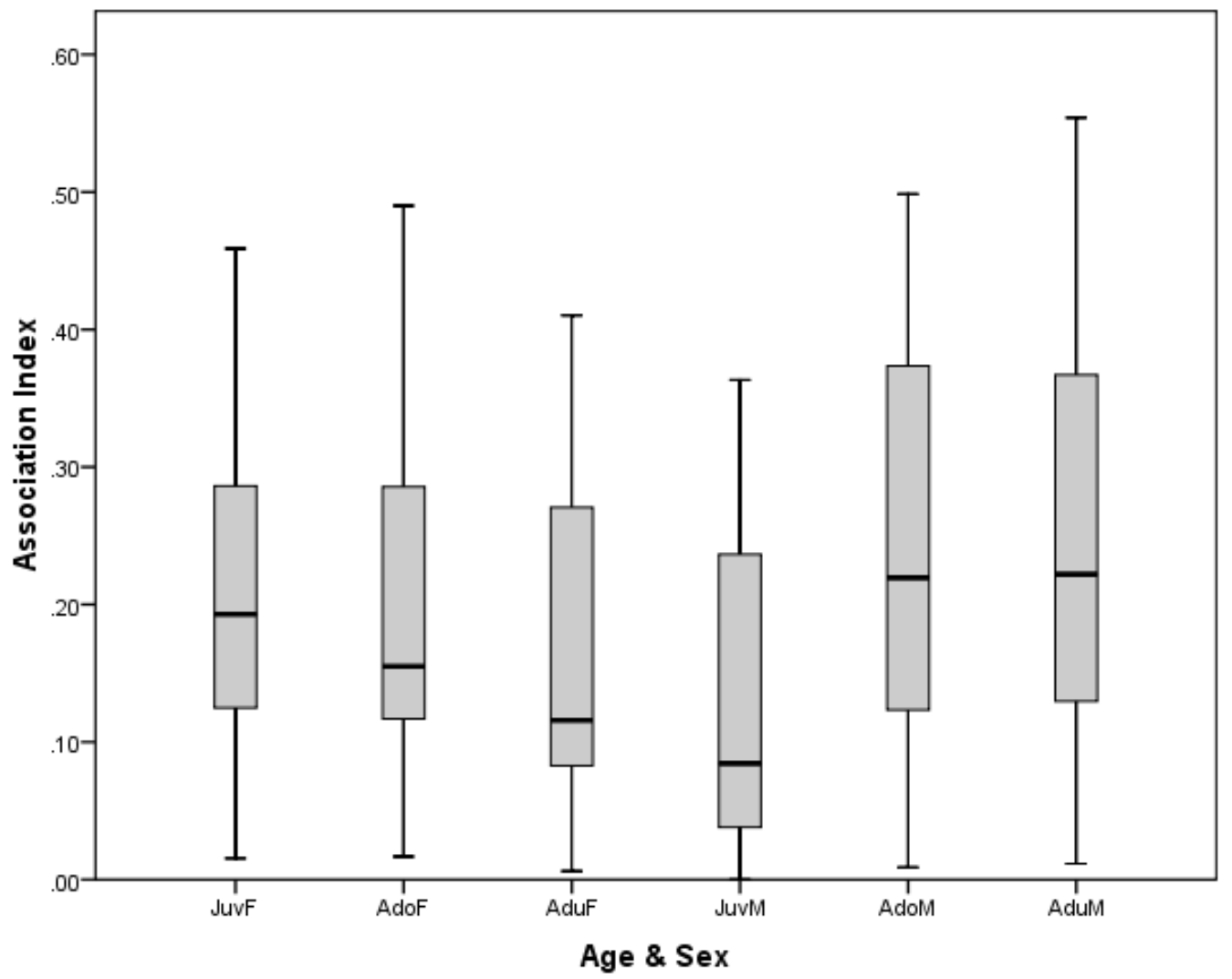


964Figure 5a

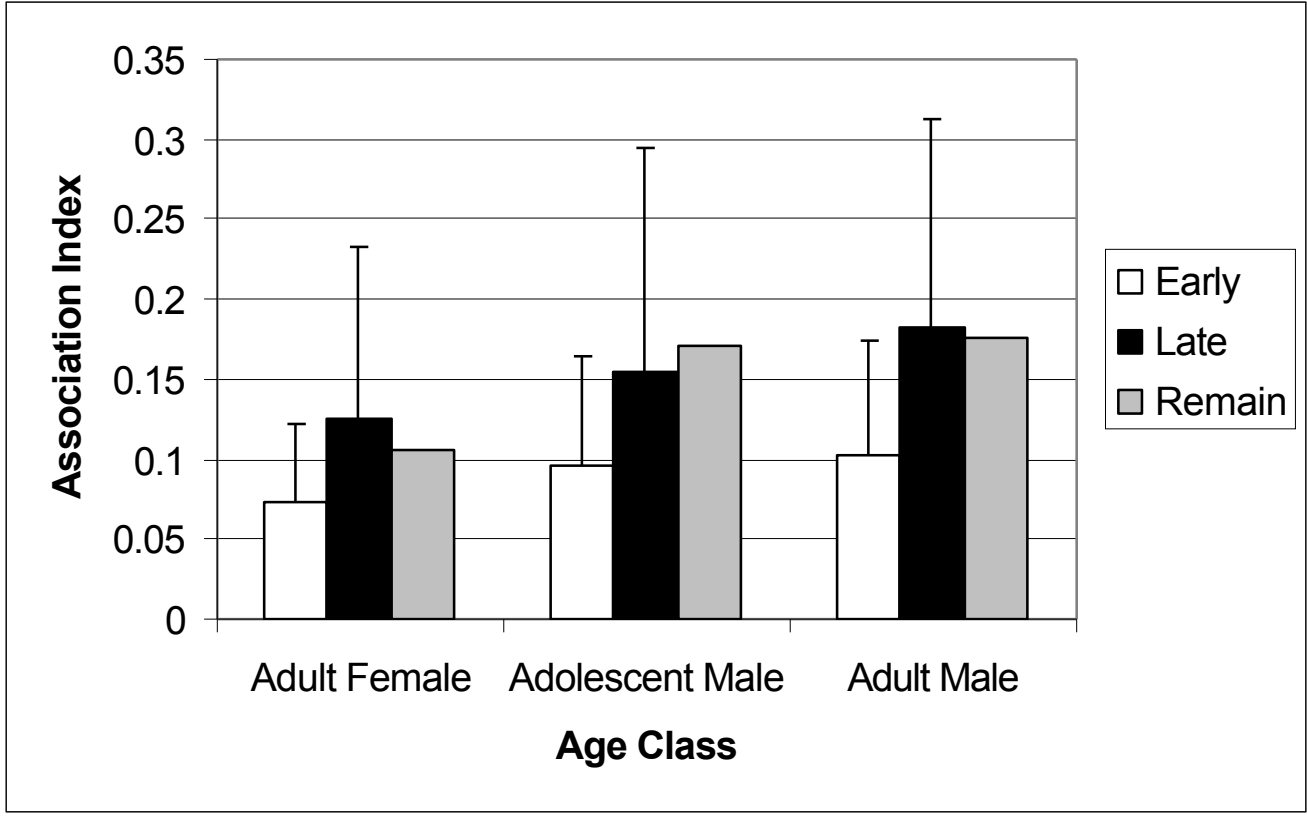

965

966Figure 5b.

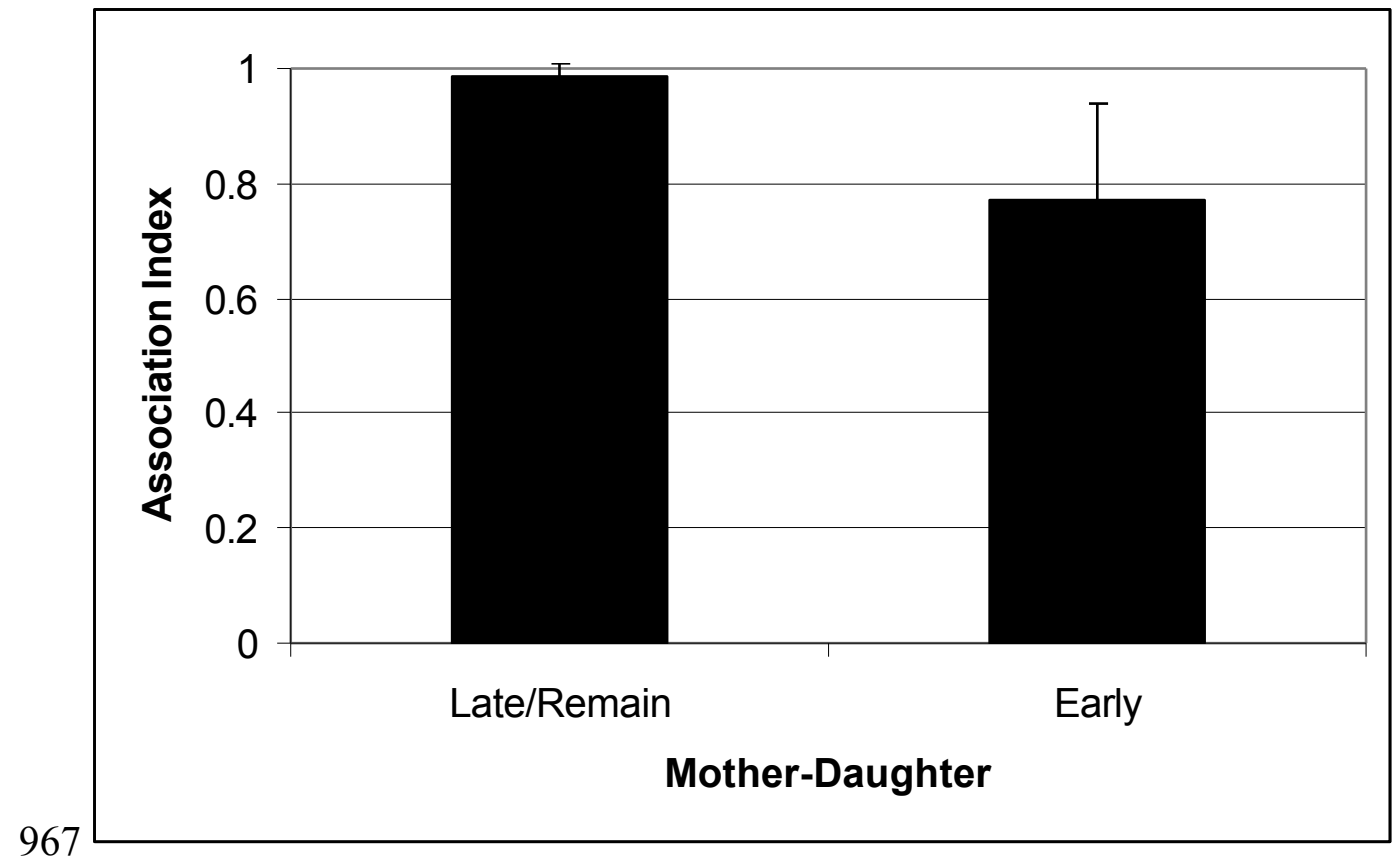


968Figure 6.

969

970(a)

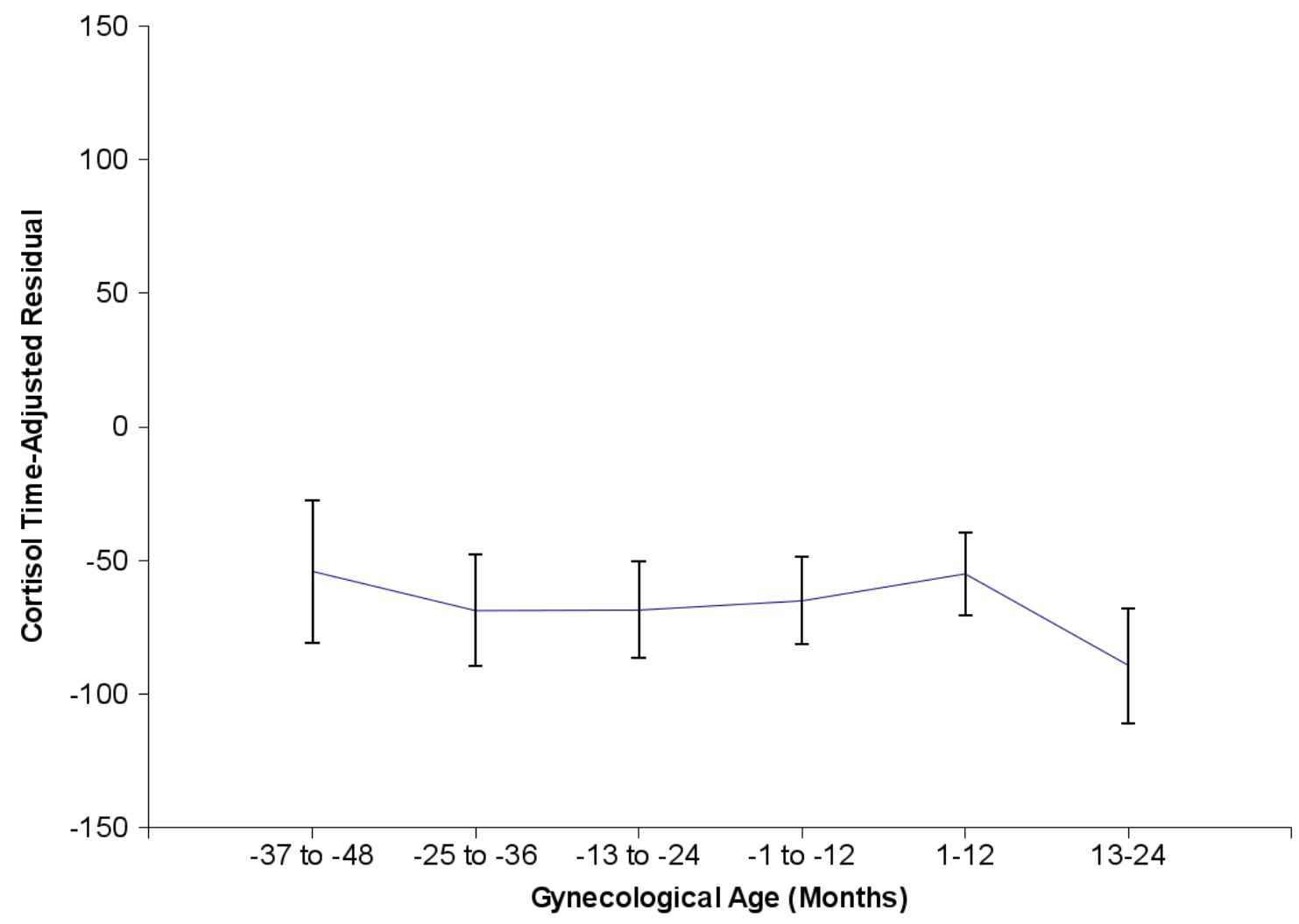

972

973

974

975

976

977

978

979

980

981

982

983

984

985

986

987

988

989

990

991

992

993

994

995

996

997

998 
999(b)

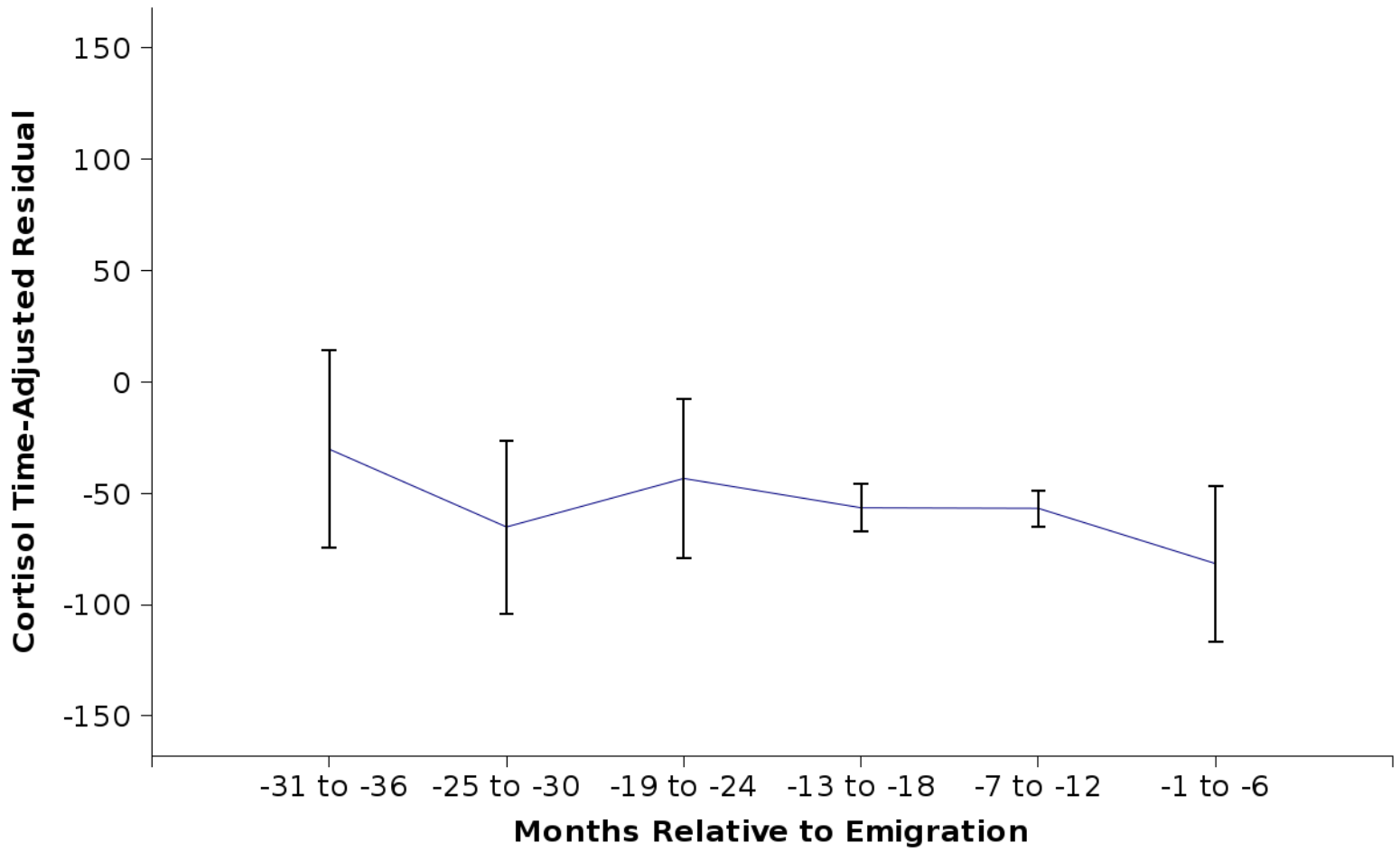


1000Figure 7a.

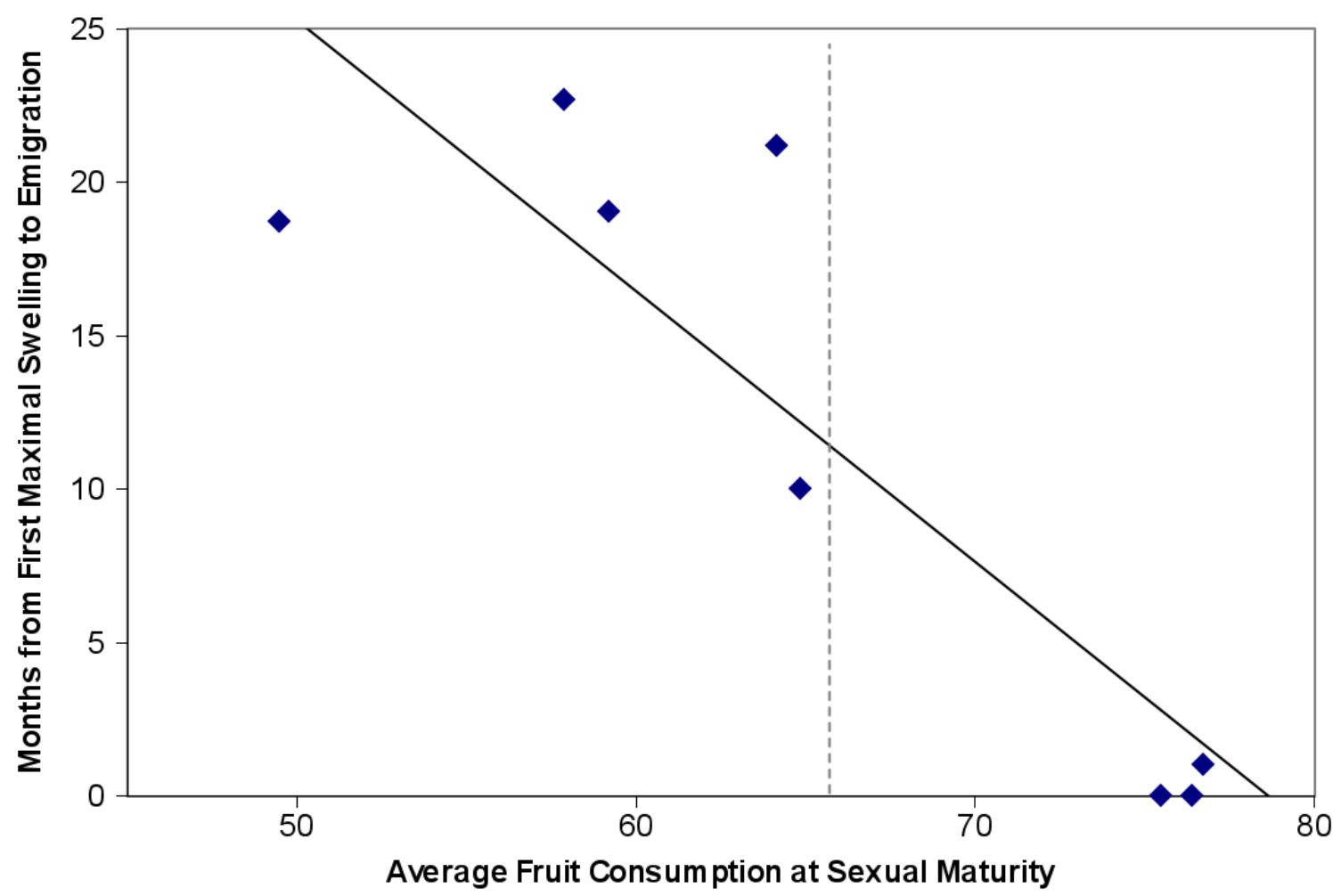


1001b)

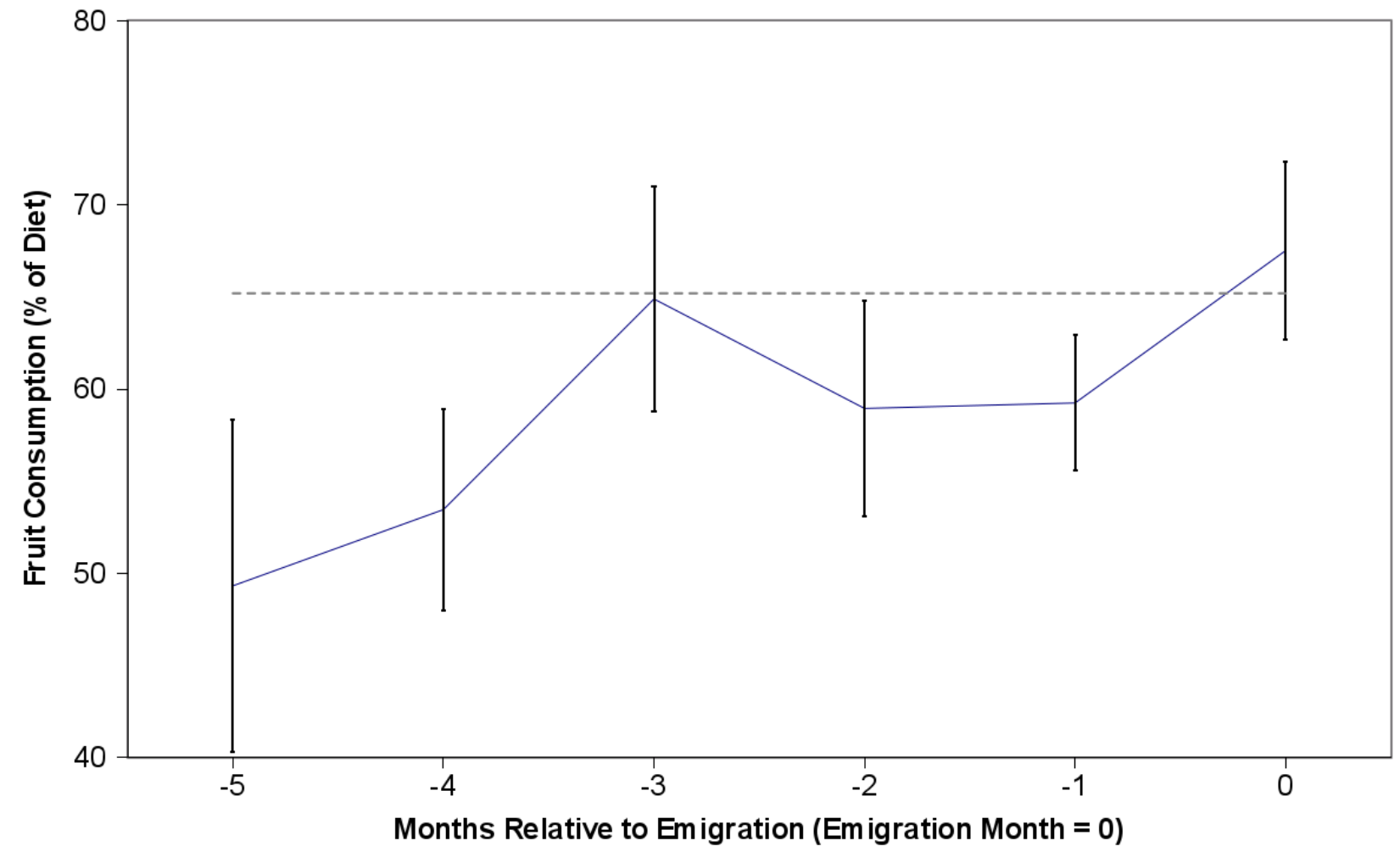

